\title{
The Scale-up of Large Pressurized Fluidized Beds For Advanced Coal-Fired Power Processes
}

\author{
Final Report
}

$\begin{array}{ll}\text { REPORT PERIOD START DATE: } & \text { October 1, } 1995 \\ \text { REPORT PERIOD END DATE: } & \text { September 30, } 1999\end{array}$

PRINCIPAL AUTHORS: Leon R. Glicksman, Michael Louge, Hesham F. Younis, Richard Tan, Mathew Hyre and Mark Torpey

DATE REPORT ISSUED: November 24, 2003

DOE AWARD NUMBER: DE-F622-95PC95228

\section{SUBMITTING}

ORGANIZATION:

\author{
Massachusetts Institute of Technology \\ Depts of Architecture and Mechanical Engineering \\ 77 Massachusetts Avenue \\ Cambridge, MA 02139 \\ and \\ Cornell University \\ Sibley School of Mechanical \& Aerospace Engineering \\ Upson Hall \\ Ithaca, NY 14853
}




\section{DISCLAIMER}

This report was prepared as an account of work sponsored by an agency of the United States Government. Neither the United States Government nor any agency thereof, nor any of their employees, makes any warranty, express or implied, or assumes any legal liability or responsibility for the accuracy, completeness, or usefulness of any information, apparatus, product, or process disclosed, or represents that its use would not infringe privately owned rights. Reference herein to any specific commercial product, process, or service by trade name, trademark, manufacturer, or otherwise does not necessarily constitute or imply its endorsement, recommendation, or favoring by the United States Government or any agency thereof. The views and opinions of authors expressed herein do not necessarily state or reflect those of the United States Government or any agency thereof. 


\begin{abstract}
This report was prepared as an account of work sponsored by an agency of the United States Government. Neither the United States Government nor an agency thereof, nor any of the their employees, makes any warranty, express or implied, or assumes any legal liability or responsibility for the accuracy, completeness, or usefulness of any information, apparatus, product, A combined-cycle High Performance Power System (HIPPS) capable of overall cycle efficiencies approaching $50 \%$ has been proposed and designed by Foster Wheeler Development Corporation (FWDC). A pyrolyzer in the first stage of the HIPPS process converts a coal feedstock into fuel gas and char at an elevated pressure of 1.4 Map. (206 psia) and elevated temperature of $930{ }^{\circ} \mathrm{C}\left(1700{ }^{\circ} \mathrm{F}\right)$. The generated char serves as the feedstock for a Pulverized Coal (PC) boiler operating at atmospheric pressure, and the fuel gas is directly fired in a gas turbine. The hydrodynamic behavior of the pyrolyzer strongly influences the quality of both the fuel gas and the generated char, the energy split between the gas turbine and the steam turbine, and hence the overall efficiency of the system.

By utilizing a simplified set of scaling parameters (Glicksman et al.,1993), a $4 / 7^{\text {th }}$ labscale cold model of the pyrolyzer operating at ambient temperature and pressure was constructed and tested. The scaling parameters matched include solid to gas density ratio, Froude number, length to diameter ratio; dimensionless superficial gas velocity and solid recycle rate, particle sphericity and particle size distribution (PSD).
\end{abstract}




\section{TABLE OF CONTENTS}

ABSTRACT

LIST OF GRAPHICAL MATERIALS ii

EXECUTIVE SUMMARY .i

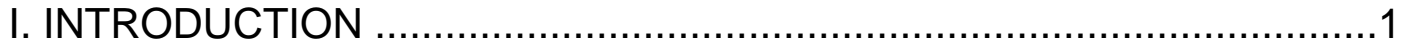

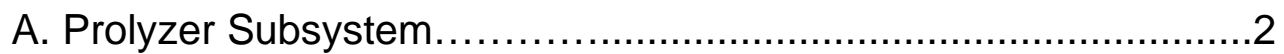

B. Model Apparatus and Experimental Procedure .....................3

II. EXPERIMENTAL …...................................................................11

A. Plastics, Cork Concentrations............................................11

B. Model Description..........................................

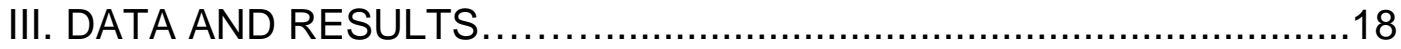

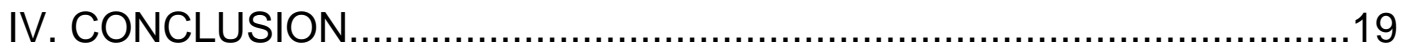

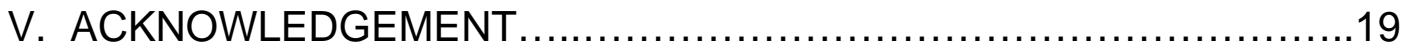

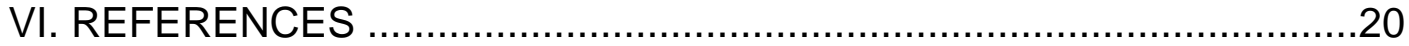




\section{LIST OF GRAPHICAL MATERIALS}

1. HIPPS Process Flow Schematic.................................. 1

2. Pilot Plant Process Flow Schematic.................................2

3. Pilot Plant Pyrolyzer Reactor.........................................

4. Cold Model Apparatus and Instrumentation........................4

5. Dimensionless PSD Plot of Char and Cork .........................5

6. Dimensionless PSD Plot of Spent Sorbent and Plastic ..................5

7. Core and Annular Wall Sampling ................................6

8. Empirical Data on Mass Fraction of Plastic and Mixture Bulk Density..7

9. Average Solid Fraction Profiles for a 25-75\% Mixture at $2 \mathrm{~m} / . \ldots \ldots \ldots . . .8$

10. Average Solid Fraction Profiles for a 50-50\% Mixture at $2 \mathrm{~m} / \mathrm{s} \ldots \ldots \ldots . .8$

11. Mass Fraction of Plastic for a 25-75\% Mixture at $2 \mathrm{~m} / \mathrm{s} . \ldots \ldots \ldots \ldots . . . .9$

12. Mass Fraction of Plastic for a $50-50 \%$ Mixture at $2 \mathrm{~m} / \mathrm{s} . \ldots \ldots \ldots \ldots . . . . .99$

13. Extended Abrupt Exit Geometry................................10

14. Average Particle Diameters for the $25 \%$ plastic $-75 \%$ cork mixture

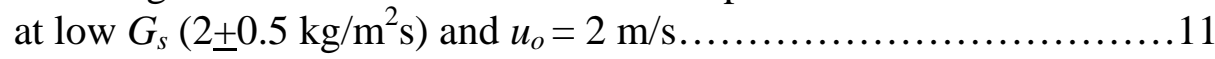

15. Average Particle Diameters for the $25 \%$ plastic - $75 \%$ cork mixture

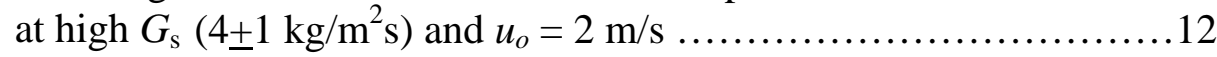

16. Individual specie solid holdup along the riser for a $50 \%$ plastic $50 \%$ cork mixture at high $G_{2}\left(4+1 \mathrm{~kg} / \mathrm{m}^{2} \mathrm{~s}\right)$ and $u_{o}=2 \mathrm{~m} / \mathrm{s} \ldots \ldots \ldots \ldots . .13$

17. Individual specie solid holdup along the riser for a $50 \%$ plastic $50 \%$ cork mixture at low $G_{2}\left(2+0.5 \mathrm{~kg} / \mathrm{m}^{2} \mathrm{~s}\right)$ and $u_{o}=2 \mathrm{~m} / \mathrm{s} \ldots \ldots \ldots \ldots . .13$

18. Individual specie solid holdup along the riser for a $25 \%$ plastic $75 \%$ cork mixture at high $G_{2}\left(4+1 \mathrm{~kg} / \mathrm{m}^{2} \mathrm{~s}\right)$ and $u_{o}=2 \mathrm{~m} / \mathrm{s}$

19. Individual specie solid holdup along the riser for a $25 \%$ plastic $75 \%$ cork mixture at low $G_{2}\left(2 \pm 0.5 \mathrm{~kg} / \mathrm{m}^{2} \mathrm{~s}\right)$ and $u_{o}=2 \mathrm{~m} / \mathrm{s} \ldots \ldots \ldots \ldots . .14$

20. A typical element showing the core-annulus division ..............15

21. Mass balance at riser exit....................................16

22. Plastic solid holdup along the riser for a $50 \%$ plastic $-50 \%$ cork mixture at $G_{s, p}=0.9 \mathrm{~kg} / \mathrm{m}^{2} \mathrm{~s}\left(G_{s, t o t a l}=2.1 \mathrm{~kg} / \mathrm{m}^{2} \mathrm{~s}\right), k=0.025 \mathrm{~m} / \mathrm{s}$ and $u_{o}=2 \mathrm{~m} / \mathrm{s}$

23. Plastic solid holdup along the riser for a $50 \%$ plastic $-50 \%$ cork mixture at $G_{s, c}=1.2 \mathrm{~kg} / \mathrm{m}^{2} \mathrm{~s}\left(G_{s, t o t a l}=2.1 \mathrm{~kg} / \mathrm{m}^{2} \mathrm{~s}\right), k=0.067 \mathrm{~m} / \mathrm{s}$ and $u_{o}=2 \mathrm{~m} / \mathrm{s}$ 


\section{EXECUTIVE SUMMARY}

This report was prepared as an account of work sponsored by an agency of the United States Government. Neither the United States Government nor an agency thereof, nor any of the their employees, makes any warranty, espress or implied, or assumes any legal liability or responsibility for the accuracy, completeness, or usefulness of any information, apparatus, project, A combined-cycle High Performance Power System (HIPPS) capable of overall cycle efficiencies approaching $50 \%$ has been proposed and designed by Foster Wheeler Development Corporation (FWDC). A pyrolyzer in the first stage of the HIPPS process converts a coal feedstock into fuel gas and char at an elevated pressure of 1.4 MPa. (206 psia) and elevated temperature of $930{ }^{\circ} \mathrm{C}\left(1700{ }^{\circ} \mathrm{F}\right)$. The generated char serves as the feedstock for a Pulverized Coal (PC) boiler operating at atmospheric pressure, and the fuel gas is directly fired in a gas turbine. The hydrodynamic behavior of the pyrolyzer strongly influences the quality of both the fuel gas and the generated char, the energy split between the gas turbine and the steam turbine, and hence the overall efficiency of the system.

By utilizing a simplified set of scaling parameters (Glicksman et al., 1993), a $4 / 7^{\text {th }}$ labscale cold model of the pyrolyzer operating at ambient temperature and pressure was constructed and tested. The scaling parameters matched include solid to gas density ratio, Froude number, length to diameter ratio, dimensionless superficial gas velocity and solid recycle rate, particle sphericity and particle size distribution (PSD).

The design has dissimilar size and density char and limestone particles which are fluidized in the pyrolyzer. The hydrodynamic behavior of these two different solids was simulated experimentally using cork and plastic with varying solid recirculation rates and a superficial gas velocity of $2 \mathrm{~m} / \mathrm{s}$. Volumetric solid fractions along the riser were measured in each case. Several sampling devices located axially along the riser enabled the collection of solid bed particles at various levels. These samples were analyzed for both average particle diameters and material concentrations (solid specie mass fraction).

The results indicate a greater presence of the coarse plastic particles at the bottom of the riser due to their significantly higher terminal velocities. A higher mass fraction of the coarse plastic particles is also observed at the wall region than in the bed core at all heights. Both the effects of varying the solids recycle rate as well as the material loading ratio are investigated. Finally, the effect of an abrupt riser exit geometry is considered and is believed to be responsible for a stronger presence of the heavier plastic particles within the riser. 


\section{Introduction}

A High Performance Power System (HIPPS) is being developed under the sponsorship of the United States Department of Energy, National Energy Technology Laboratory. This system is a coal fired combined cycle that uses a High Temperature Advanced Furnace (HITAF) that transfers heat to both air and steam working fluids. The Foster Wheeler design uses a pyrolyzation process to convert a pulverized coal feedstock into two components, a low-Btu fuel gas and solid char. Figure 1 illustrates the HIPPS process flow schematic as defined for a commercial plant.. The fuel gas exhaust from the reactor is directly connected to the gas turbine and is burned with the air from the compressor. The generated char provides the feedstock for the HITAF. Systems of this type are capable of over 47 percent efficiency.

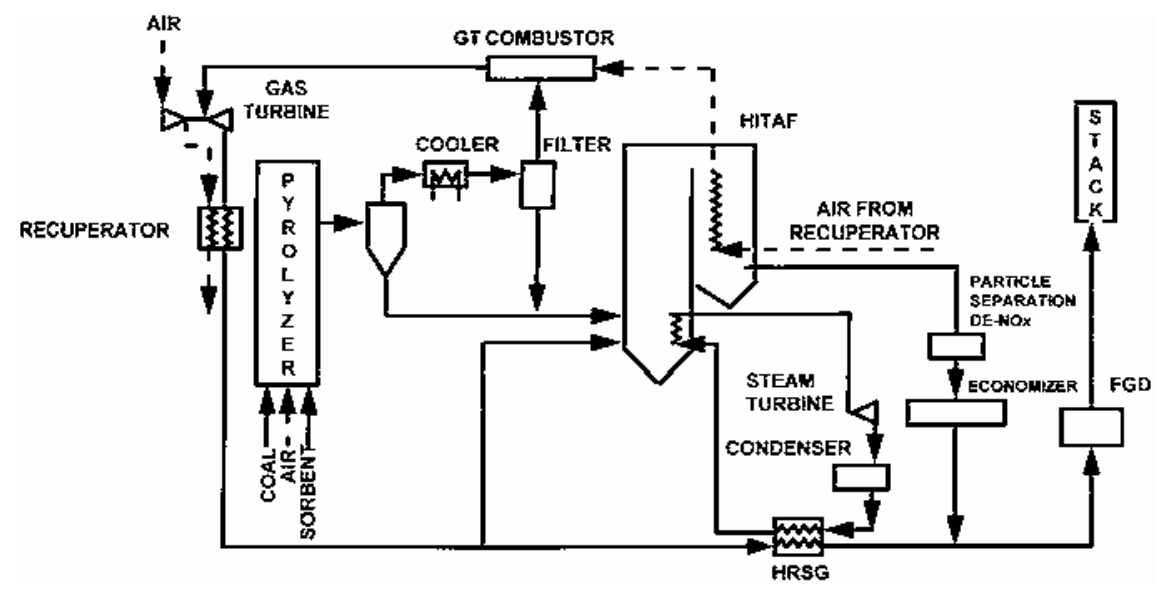

Figure 1 HIPPS Process Flow Schematic

In Phase 1 of the HIPPS project, a conceptual design of a $300 \mathrm{MW}$ commercial plant was developed. Economic analysis of this plant relative to a PC boiler of equivalent size indicates that the HIPPS plant will have a 15 percent lower cost of electricity. Phase 2 of the project is now in progress and includes experimental pilot scale testing of both a coalfired pyrolyzer and a char combustor. The Phase 2 work is being done to support the design of a prototype plant in Phase 3 of the overall project.

Cold scale modeling of fluidized beds has proven to be a powerful tool in predicting their performance. Various researchers have developed their own sets of scaling parameters that govern the hydrodynamic behavior of fluidized beds (Scharff et al., 1978; Glicksman, 1984, 1988,1993; Horio et. al., 1986, 1989). This work uses Glicksman's simplified set of scaling parameters (Glicksman et. al., 1993) to simulate the hydrodynamics of FWDC's pressurized circulating fluidized bed (PCFB) pyrolyzer:

$$
\frac{\rho_{s}}{\rho_{f}} \frac{u_{o}^{2}}{g D} \frac{u_{o}}{u_{m f}} \frac{L}{D} \frac{G_{s}}{\rho_{s} u_{o}} \phi_{s} \quad P S D
$$

This set of scaling parameters has been previously verified for single particle suspensions in PCFBs (Hyre et. al., 1997). Here, the use of the simplified scaling has been extended to simulate the hydrodynamics of dissimilar solids in PCFBs. The simplified set of scaling parameters allows for the bed dimension to be proposed independently. Thus, a $4 / 7^{\text {th }}$ scale cold model of the hot bed was built and tested at the Massachusetts Institute of Technology (MIT). The hot bed uses dissimilar size and density char and limestone particles which are fluidized in the pyrolyzer. In this case, the ratio of char density to gas 
density as well as the ratio of limestone density to gas density must be matched in the model. Using cork and plastic, respectively, and air at ambient temperature and pressure as the fluidizing gas, the above parameters were matched between the cold scale model and the hot bed. The results presented here will be used to predict the hot bed hydrodynamics in future tests to be run at FWDC.

\section{Pyrolyzer Subsystem}

The experimental testing of the pyrolyzer subsystem is being performed at FWDC's R\&D facility in Livingston, N.J. The overall pilot plant process flow schematic is depicted in Figure 2. The pyrolyzer is currently operated as a bubbling fluidized bed to generate a low-Btu fuel gas and a solid char. Future tests will investigate the circulating mode. In a commercial/ demonstration plant the fuel gas will be burned in a gas turbine, and the char will be fired with pulverized fuel burners in the HITAF. In the pilot plant, however, the fuel gas is flared, and the char is collected and stored for future tests at a separate burner test facility in Dansville, N.Y.

The reactor, as illustrated in Figure 3, has a stepped inner diameter starting from $25 \mathrm{~cm}$ in the bottom section, stepping to $30 \mathrm{~cm}$ approximately $1.1 \mathrm{~m}$ above the injection nozzle, and finally expanding to $36 \mathrm{~cm}$ in the freeboard. The total height of the refractory lined reactor is approximately $10.7 \mathrm{~m}$. Coal and limestone are pneumatically conveyed through a central feed pipe into the bottom of the reactor bed. The pulverized coal introduced into the reactor is partially gasified and attrited to meet the requirements of the char combustor. The generated char is elutriated out of the reactor with the fuel gas and carried over to a high temperature ceramic filter to remove the particulate from the gas stream. The fuel gas is depressured through an orifice plate to simulate gas turbine operation. The collected char is depressured through a lock hopper system and pneumatically conveyed with nitrogen to a baghouse. Char is removed from the baghouse via a rotary valve and stored for future char combustion tests.

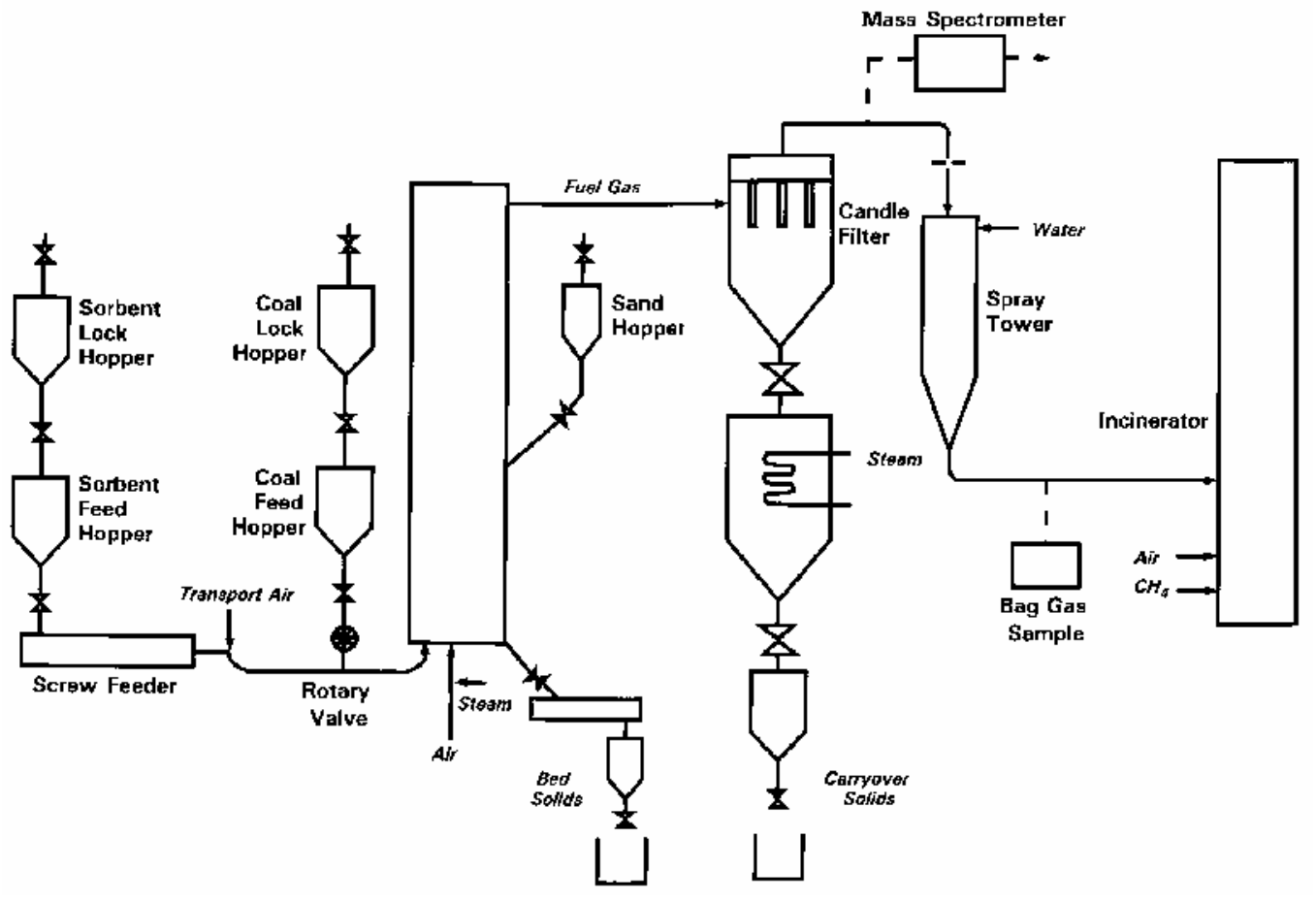

Figure 2 Pilot Plant Process Flow Schematic 


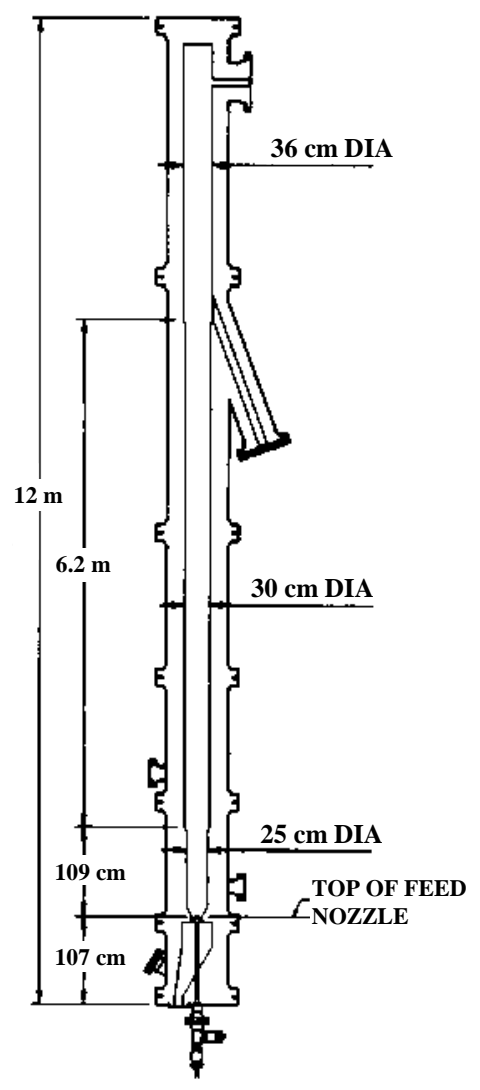

Figure 3 Pilot Plant Pyrolyzer Reactor

\section{Model Apparatus and Experimental Procedure}

The MIT cold scale model (see Figure 4) is $4 / 7^{\text {th }}$ the size of the Foster Wheeler pilot plant. The distance between the inlet and the outlet of the cold model is $5.7 \mathrm{~m}$ while the inside diameter of the riser is $10.2 \mathrm{~cm}$. An $L / D$ ratio of 56 is identical to that of the pilot plant. Air to the riser is supplied through a central jet at the bottom of the riser. The MIT model is being operated to investigate the performance of the pyrolyzer as a circulating bed to anticipate future hot bed performance.

A primary cyclone at the riser exit acts as the separation device. Solid particles move down the return leg for re-circulation. Air and finer particles which escape the primary cyclone separation exit through the top of the cyclone and enter a secondary cyclone which also drains back into the return leg. A filter box is connected to the exhaust of the secondary cyclone to filter out any extra fines which escape both cyclone separators. All cases have been run at a superficial gas velocity $u_{0}$ of $2 \mathrm{~m} / \mathrm{s}$.

Two kinds of particles were used in experiments; granulated cork and polyethylene plastic. The solid densities of which are 242 and $905 \mathrm{~kg} / \mathrm{m}^{3}$, respectively. The mixture was prepared by matching individual dimensionless PSDs with that of the hot bed materials. This resulted in a Sauter mean diameter of cork of $92 \mu \mathrm{m}$ and plastic of 283 $\mu \mathrm{m}$. Two different mixtures were prepared and tested: $25 \%$ plastic - $75 \%$ cork and 50\% plastic - 50\% cork by mass. 


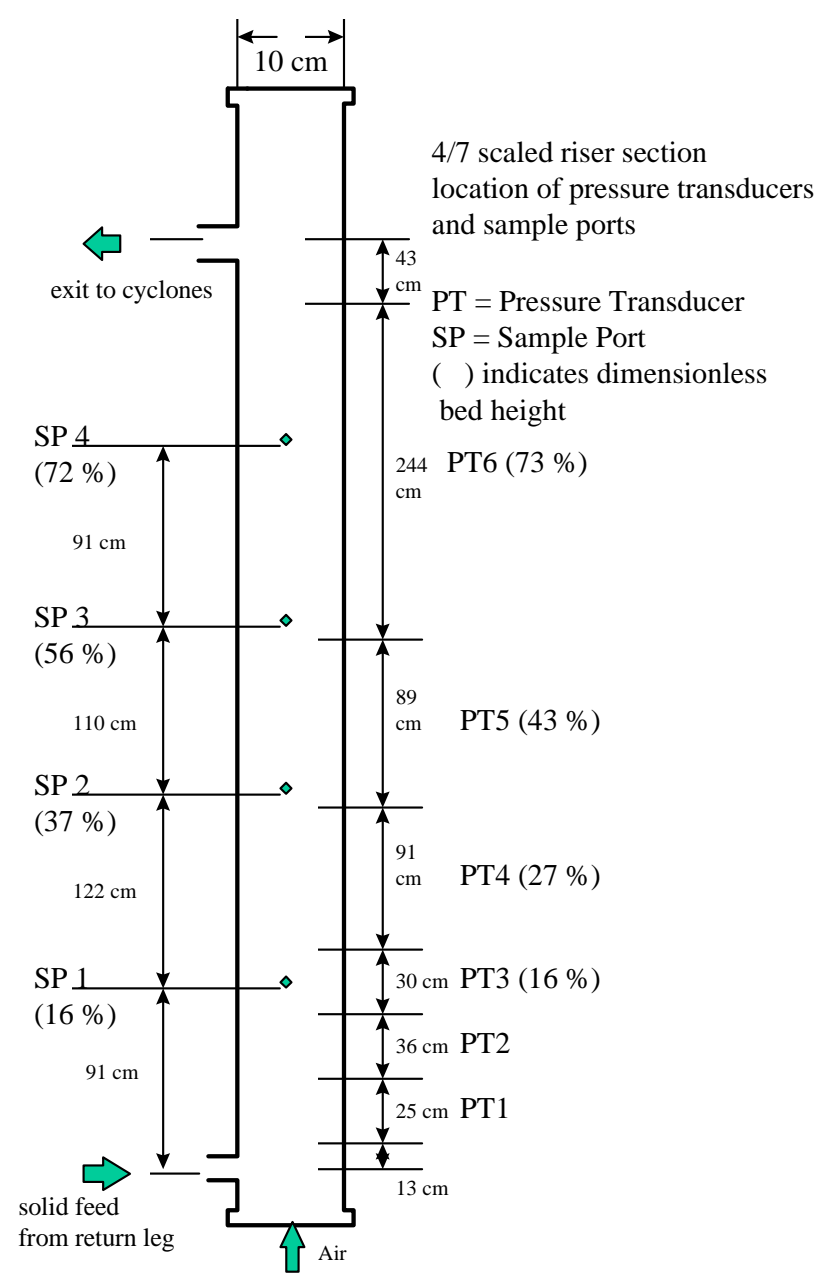

Figure 4 Cold Model Apparatus and Instrumentation

Further details of particle sizes and terminal velocities are included in Table 1. Each mixture of particular composition was tested twice; at a high $\left(4 \pm 1 \mathrm{~kg} / \mathrm{m}^{2} \mathrm{~s}\right)$ and low $(2 \pm$ $0.5 \mathrm{~kg} / \mathrm{m}^{2} \mathrm{~s}$ ) solids recycle rate. The riser was grounded at various locations and riser walls were coated with conductive floor wax to eliminate any electrostatic effects, which are often of concern when operating with fine particles.

\begin{tabular}{|c|c|c|c|c|c|}
\hline PLASTIC & & CORK & & \\
\hline$d_{p}(\mu \mathrm{m})$ & $\begin{array}{c}\text { \% Under by } \\
\text { Mass }\end{array}$ & $\begin{array}{c}u_{t}(\mathrm{~m} / \mathrm{s}) @ \\
d_{p} @\end{array}$ & $d_{p}(\mu \mathrm{m})$ & $\begin{array}{c}\text { \% Under by } \\
\text { Mass }\end{array}$ & $u_{t}(\mathrm{~m} / \mathrm{s}) @ d_{p}$ \\
\hline 212 & 27 & 0.6 & 63 & 21 & 0.02 \\
\hline 500 & 64 & 1.6 & 106 & 48 & 0.06 \\
\hline 710 & 81 & 2.1 & 212 & 82 & 0.20 \\
\hline 1000 & 92 & 2.7 & 355 & 93 & 0.43 \\
\hline 1400 & 100 & 3.3 & 500 & 100 & 0.64 \\
\hline
\end{tabular}

Table 1 Particle size distributions and terminal velocities

In another series of tests the mean particle diameter for the char and cork are $46 \mu \mathrm{m}$ and $40 \mu \mathrm{m}$ respectively. The mean particle diameter for the spent sorbent and plastic are 190 $\mu \mathrm{m}$ and $160 \mu \mathrm{m}$ respectively. 


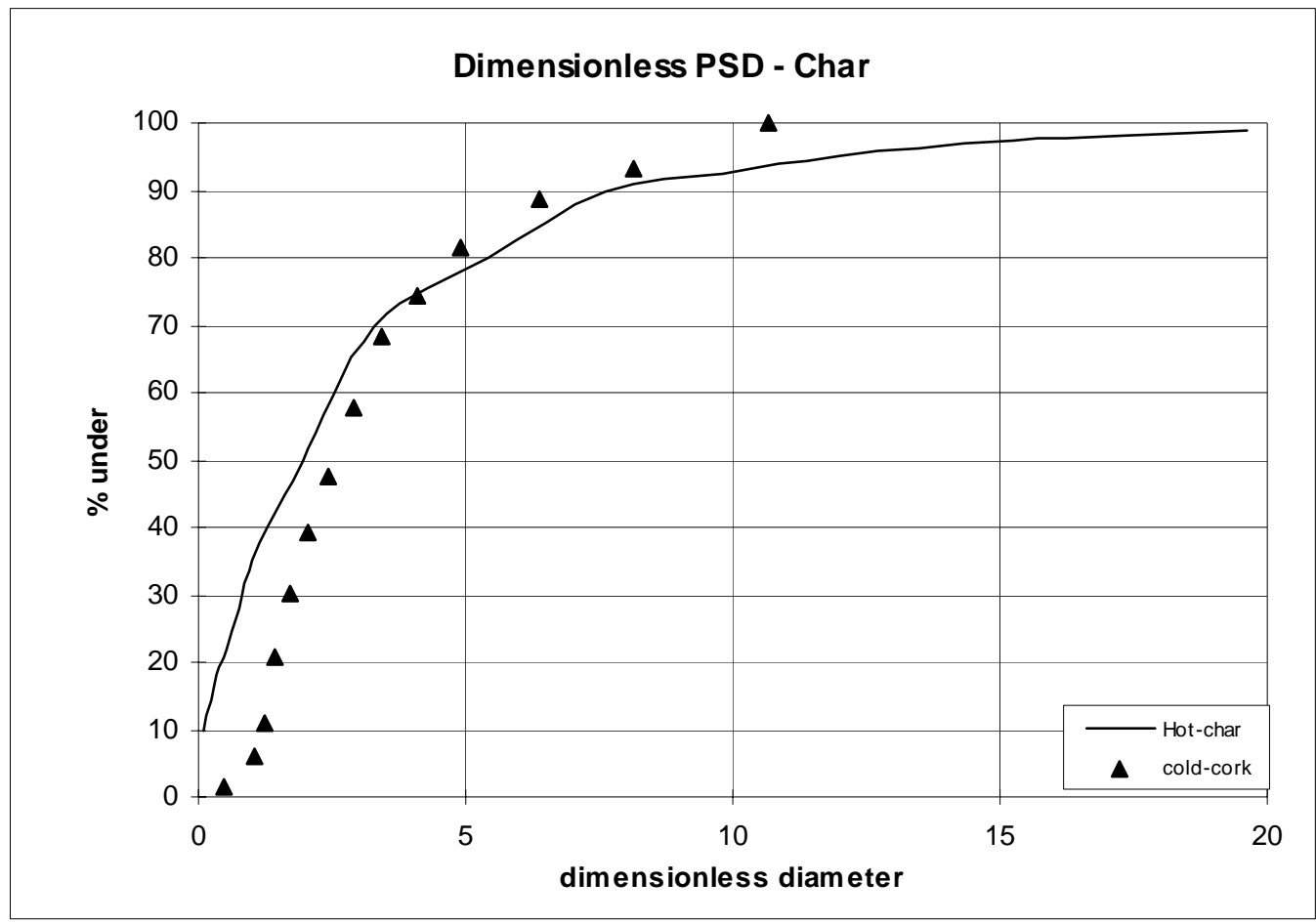

Figure 5 Dimensionless PSD Plot of Char and Cork

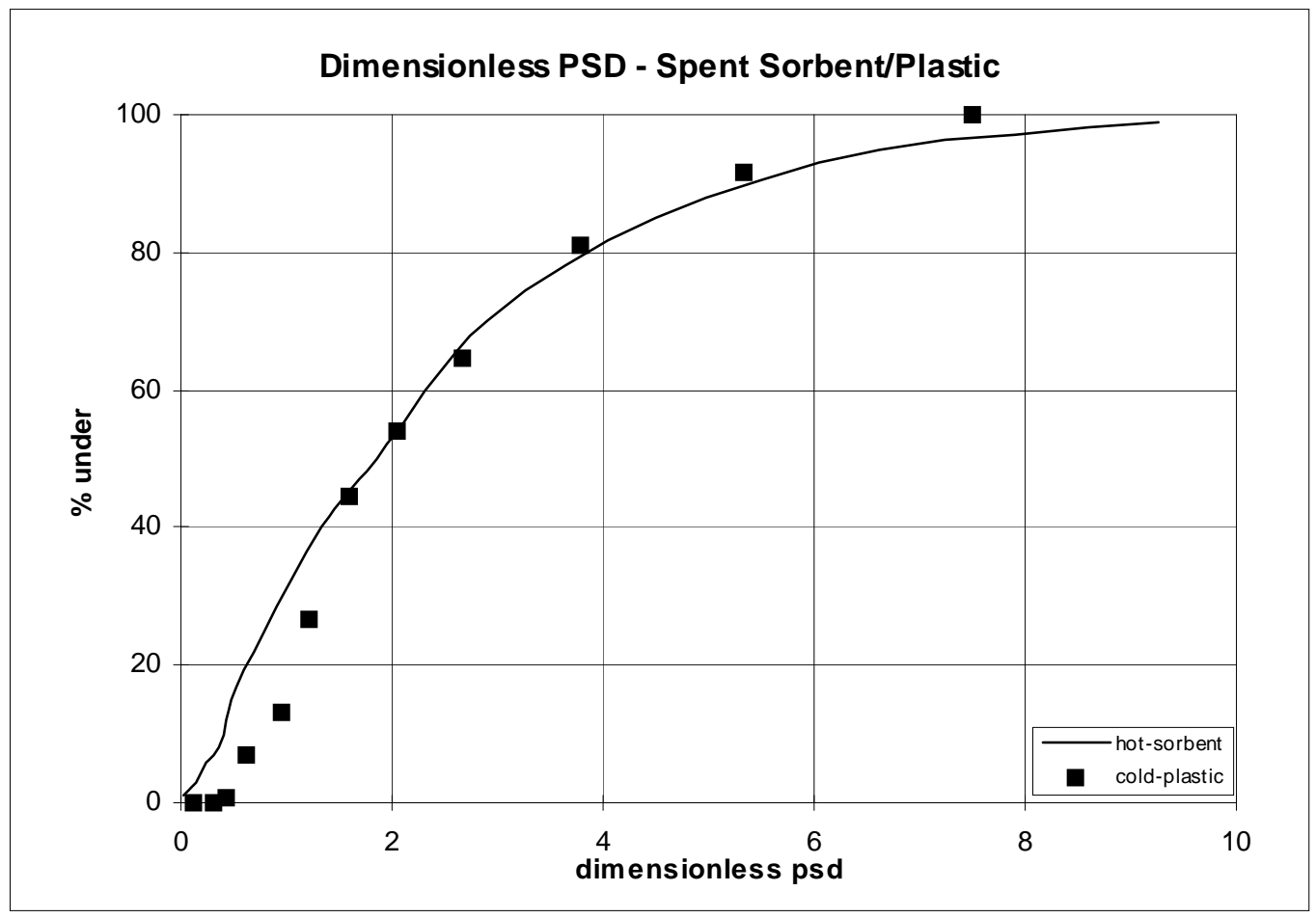

Figure 6 Dimensionless PSD Plot of Spent Sorbent and Plastic

Pressure taps (6 in total) have been drilled axially along the wall of the riser at $45^{\circ}$ downward so as to prevent the accumulation of particles at the tap openings. Purge air is also supplied to keep the taps clear. Pressure transducers were calibrated and connected to a PC data acquisition system. Nine sampling ports capable of drawing solid samples from the riser during a test run are installed throughout the bed. Eight of the nine sampling ports are installed and spaced evenly along the entire height of the riser; four of which draw samples from the core and the other four draw annular samples from the riser wall. Each location labeled "SP" on Figure 4 contains both an annular and a core Final Report DE-FG22-95PC95228 
sampling port. Figure 7 clearly illustrates the difference between annular and core sampling. The last of the nine ports is placed past the riser exit (at the entrance to the return leg) to capture a sample of particles escaping the riser. Each sample is analyzed for both solid specie mass fraction and average particle diameter.

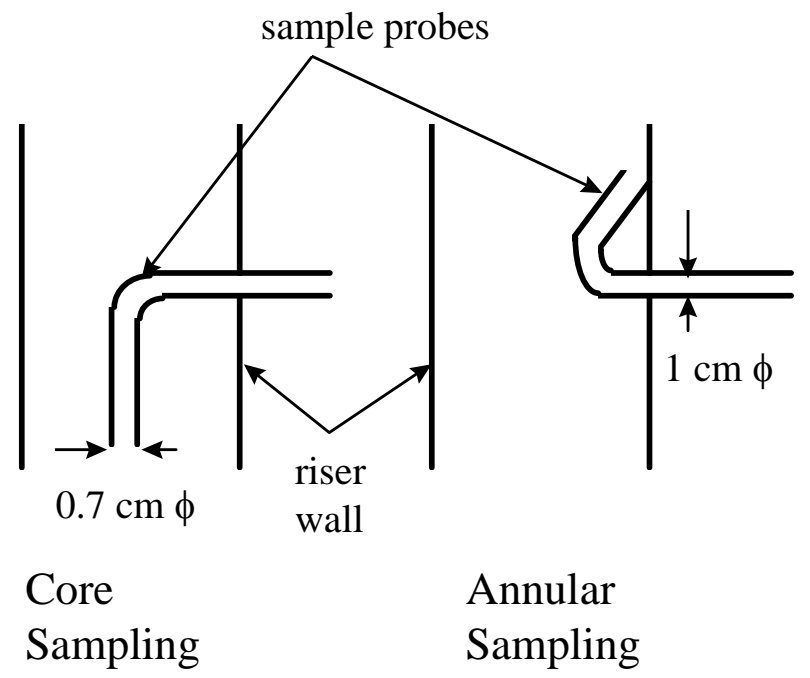

Figure7 Core and Annular Wall Sampling

Table 1 illustrates that most of the plastic particles are in the size range greater than 212 $\mu \mathrm{m}$. Samples collected with only fine plastic particles (less than $212 \mu \mathrm{m}$ ) and cork have consistently shown a bulk density identical to that of pure cork (due to the much smaller fraction of fine plastic present within). This observation aided the separation of the two materials in any given sample. A $212 \mu \mathrm{m}$ sieve is used to separate the majority of the plastic from the cork. Two pre-prepared calibration curves are then used to determine mass fractions for particles that are larger than $212 \mu \mathrm{m}$, while particles less than $212 \mu \mathrm{m}$ are assumed to be solely composed of cork. One calibration curve is for particles mostly in the range of 212-355 $\mu \mathrm{m}$ while the other is for a range from $212-1000 \mu \mathrm{m}$. The first is better suited for the $25 \%$ plastic - $75 \%$ cork mixture and the second for the $50 \%-50 \%$ mixture. The calibration curves translate the bulk density of a sample to mass fraction of plastic in that sample. The curves were prepared by premixing known fractions of cork and plastic in the size range above $212 \mu \mathrm{m}$ and measuring the resulting bulk density of the mixture (only after a consistent degree of compacting has been done). A straight line fit is then used to relate mass fraction of plastic to measured bulk density. This process introduces regression errors which are presented with the data. An error estimate for the negligence of the smaller plastic particles (less than $212 \mu \mathrm{m}$ ) has also been carried out. It has been shown that in the worst case, the mass fraction of plastic is underestimated by about $8 \%$.

Data from the pressure transducers is used to calculate the cross-sectional averaged solids fraction (overall solids holdup) using:

$$
(1-e)=\frac{\Delta P}{\rho_{s} g \Delta h}
$$

where $\rho_{s}$ is the local solids density estimated by:

$$
\rho_{s}=x_{p} \rho_{p}+\left(1-x_{p}\right) \rho_{c}
$$




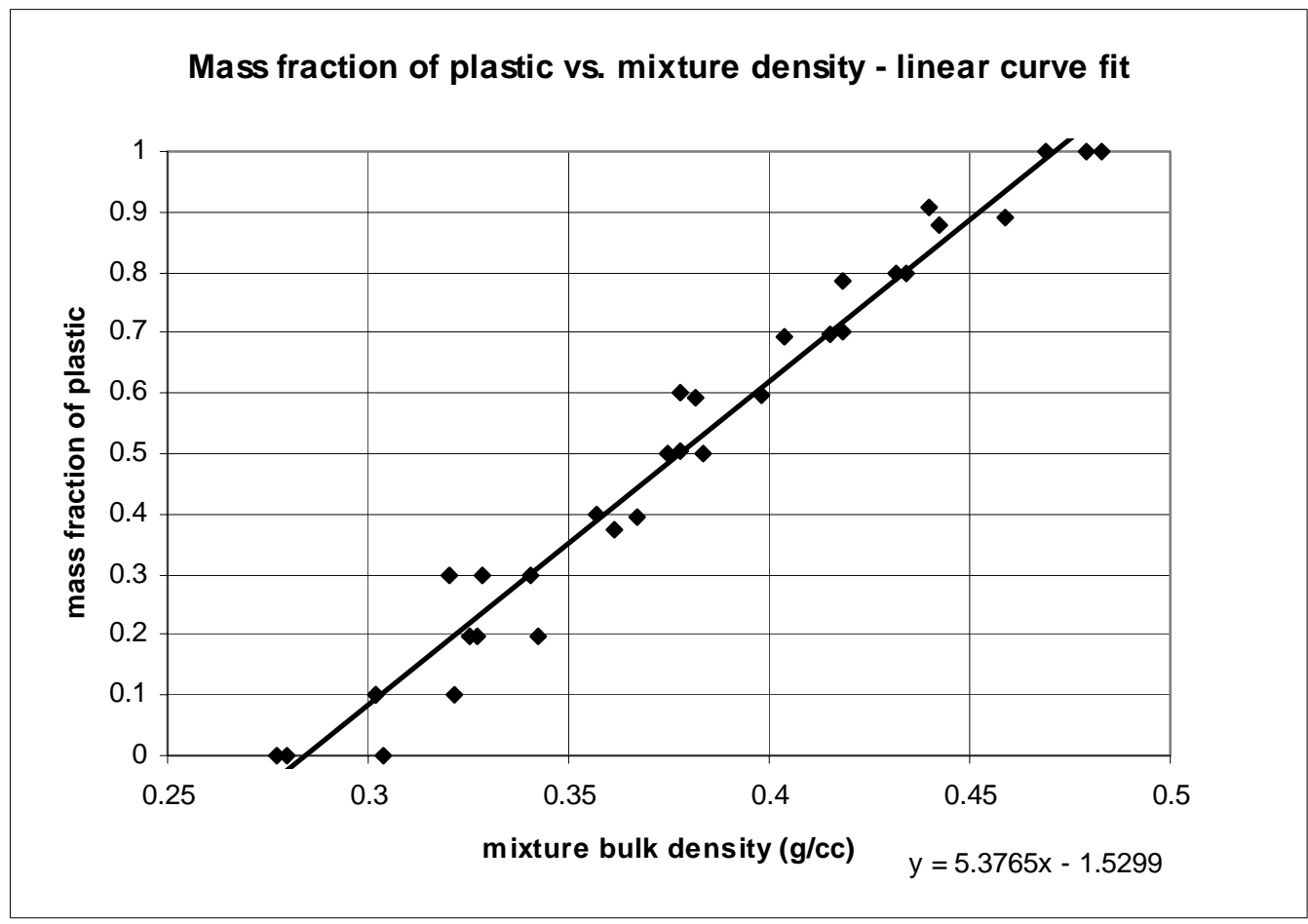

Figure 8 Empirical Data on Mass Fraction of Plastic and Mixture Bulk Density

The average mass fraction of plastic, $x_{p}$, is obtained using data from both core and annular samples at each height. There is a higher percentage of coarse particles at the riser wall as compared to the core. It is thereby necessary to use an average between the riser core and annulus to more accurately represent the true mass fraction at a particular cross-section. This is in contrast to the procedure of Bai et. al. (1994) who only use wall samples to estimate the cross-sectionally averaged fraction of coarse.

Individual plastic and cork holdups are then calculated from the overall solids holdup:

$$
\begin{aligned}
& (1-e)_{p}=x_{p}(1-e) \\
& (1-e)_{c}=\left(1-x_{p}\right)(1-e)
\end{aligned}
$$

Data from pressure transducers 1 and 2 is not used in calculating solids holdups at these cross-sections due to the presence of a deceleration region as air is injected into the riser through a bottom central jet.

Solid fraction profiles and mass fraction of the coarse (plastic) at a superficial velocity of $2 \mathrm{~m} / \mathrm{s}$ with different recirculation rates were measured for two mixtures, namely the 25$75 \%$ mixture and the $50-50 \%$ mixture. The $25-75 \%$ mixture contained $25 \%$ of plastic and $75 \%$ of cork by mass (or $8.4 \%$ of plastic and $91.6 \%$ of cork by volume) and the $50-50 \%$ mixture contains $50 \%$ of plastic and cork by mass (or $21.6 \%$ of plastic and $78.4 \%$ of cork by volume). The average solid fraction profiles are presents in Figure 7 and Figure 8. The mass fractions of coarse (plastic) are presented in Figure 9 and Figure 10. The mass fraction at the right hand side of Figure, at $100 \%$ bed height are actually the values measured at the exit of the first cyclone. 


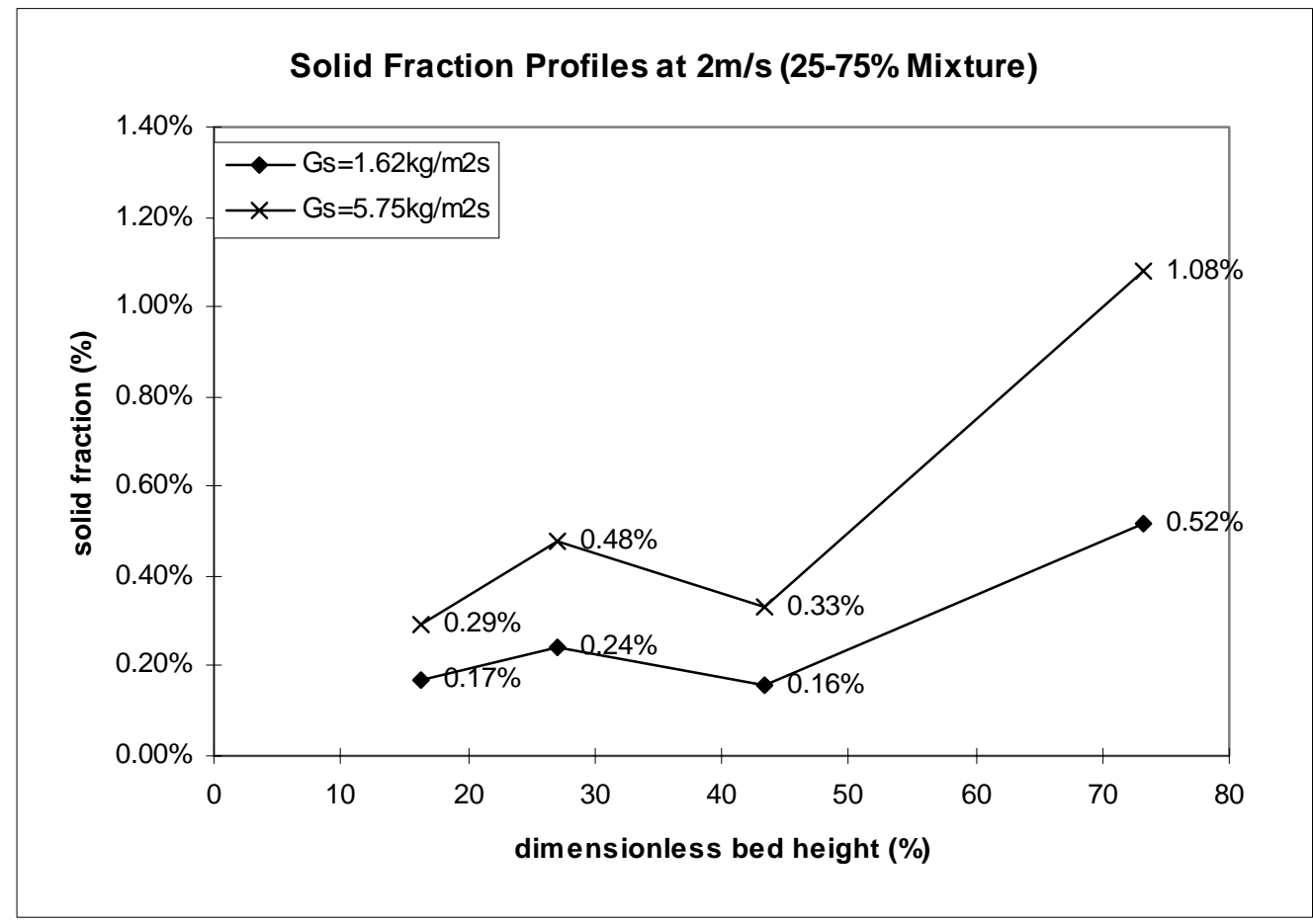

Figure 9 Average Solid Fraction Profiles for a 25-75\% Mixture at 2 m/s

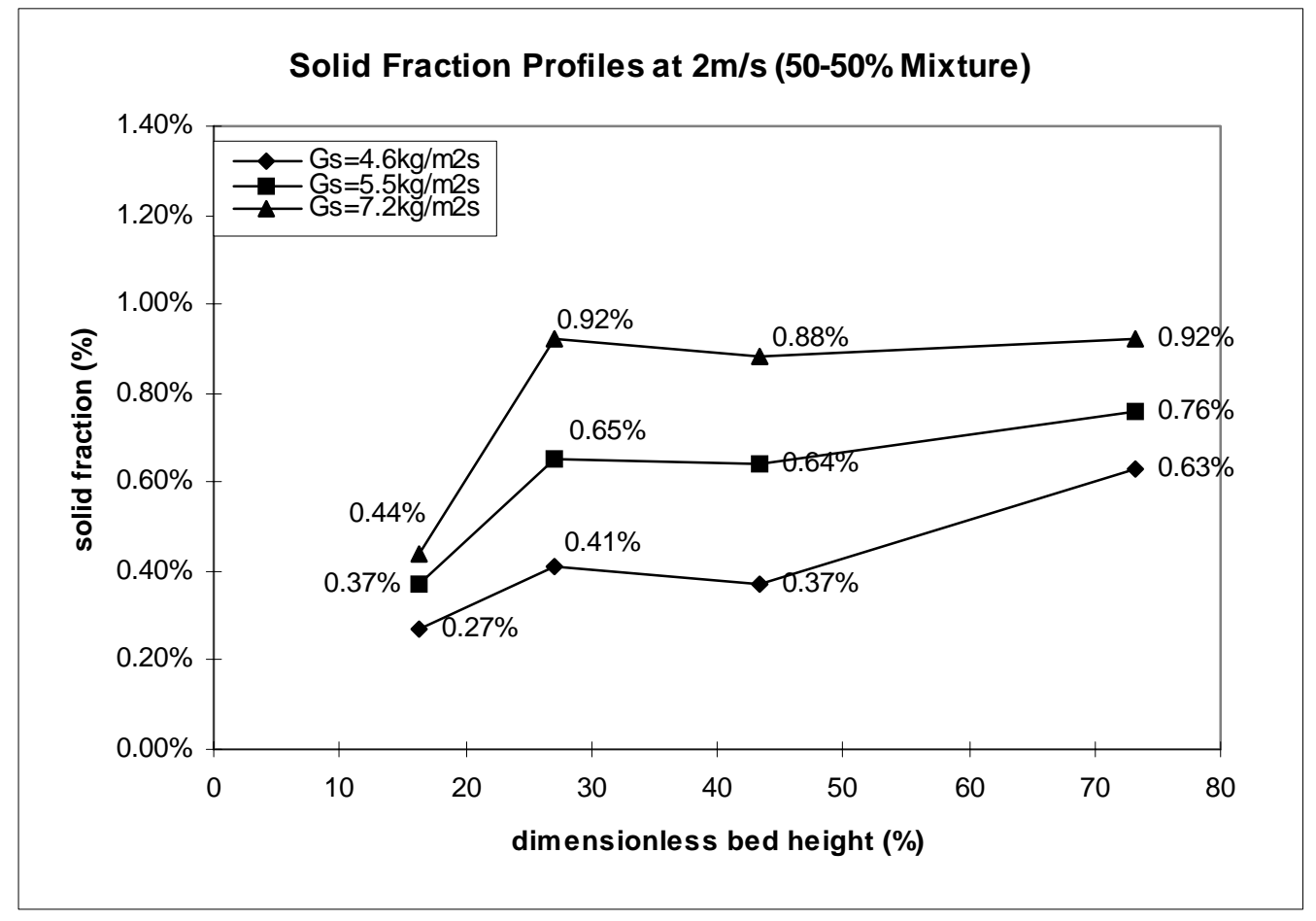

Figure 10 Average Solid Fraction Profiles for a 50-50\% Mixture at 2m/s 


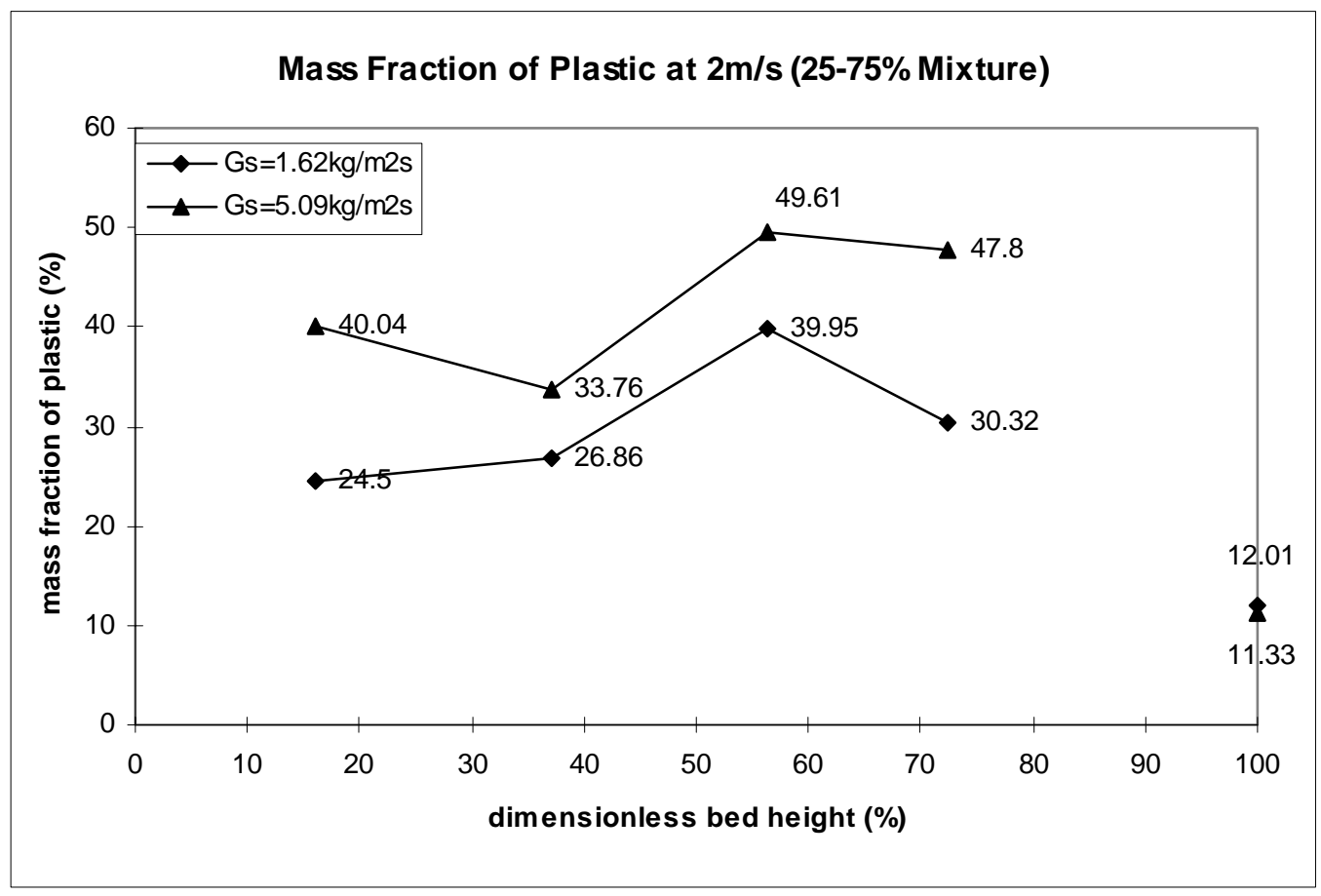

Figure 11 Mass Fraction of Plastic for a 25-75\% Mixture at $2 \mathrm{~m} / \mathrm{s}$

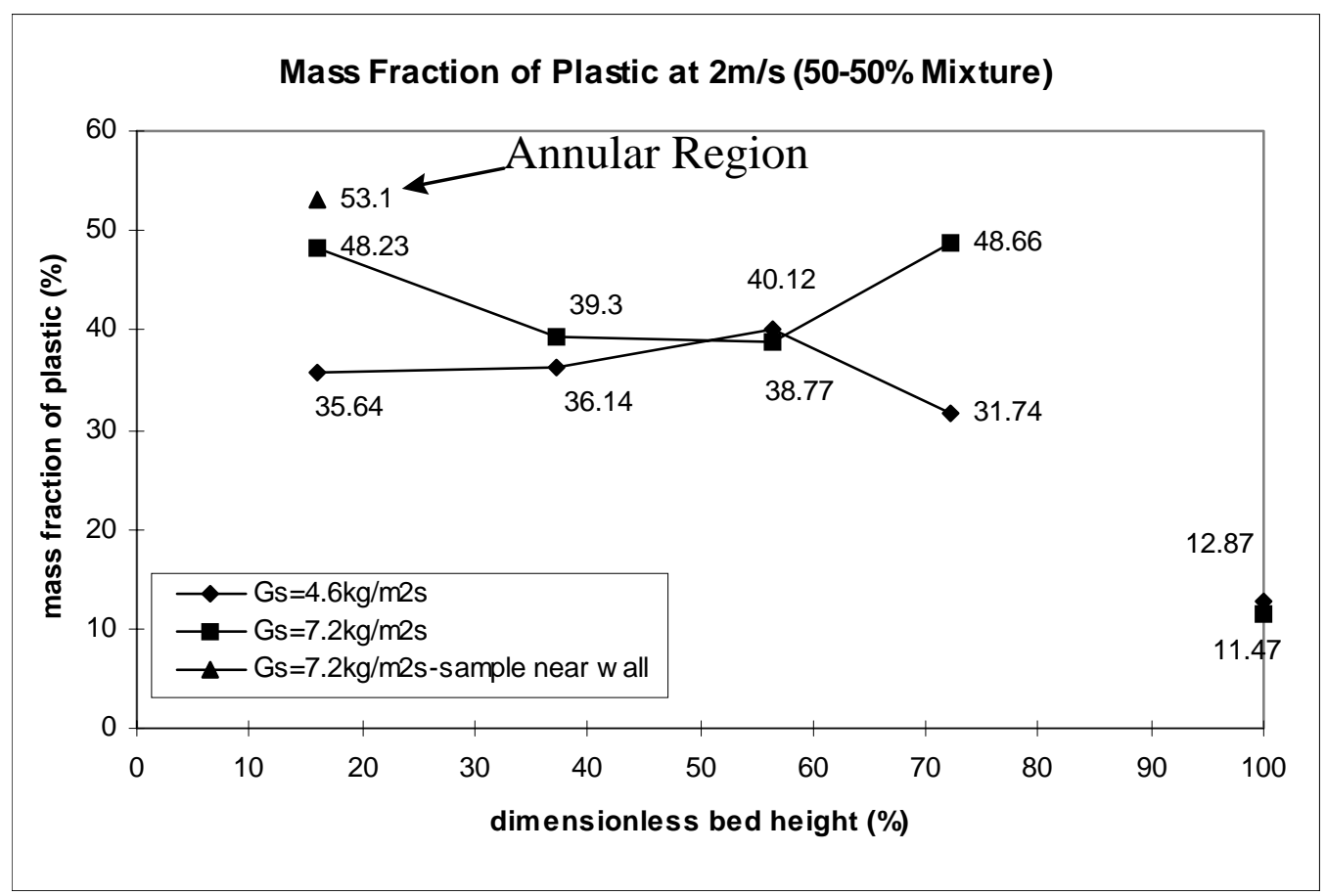

Figure 12 Mass Fraction of Plastic for a 50-50\% Mixture at $2 \mathrm{~m} / \mathrm{s}$

A general trend for most of the solid fraction profiles, especially the ones with a low concentration of plastic show an increase of solid concentration near the top of the riser, in the range of approximately $72 \%$ dimensionless bed height. This phenomenon can be explained most appropriately by the extended abrupt exit geometry, as other investigators (Brereton and Grace (1994)) with a similar exit geometry experienced the same 'solid pile-up' near the top. The exit geometry of the cold model can be described as extended abrupt as shown in Figure 15. 


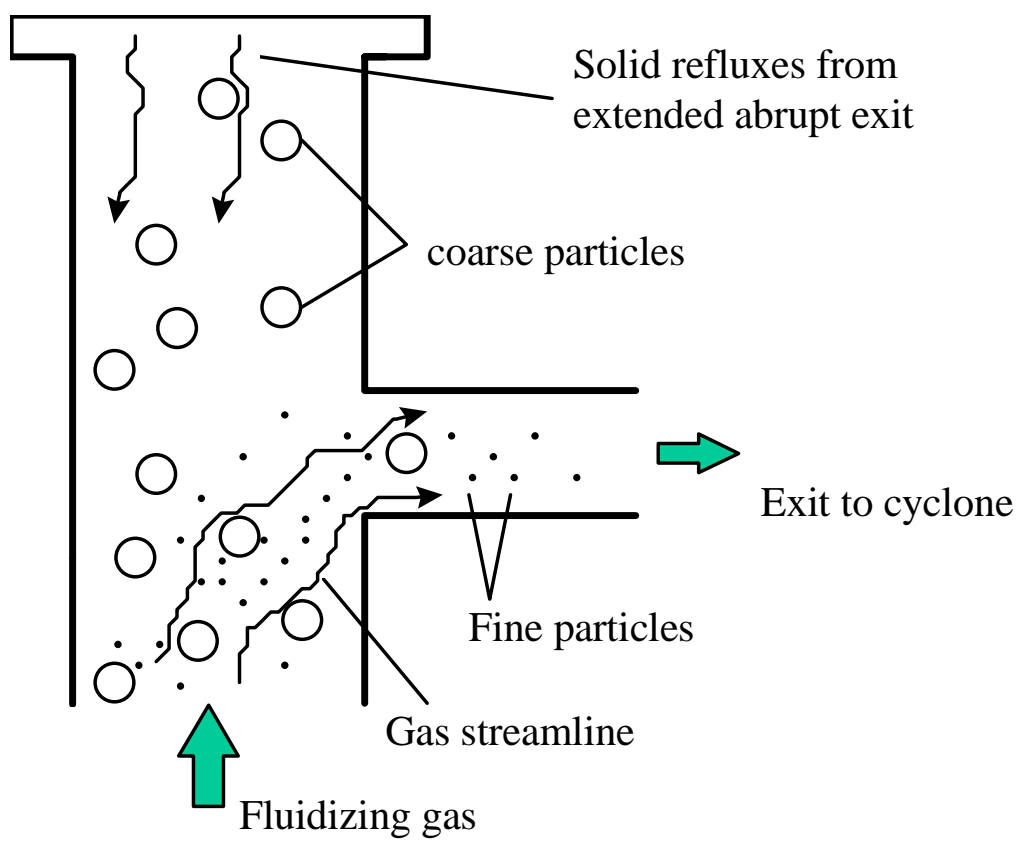

Figure 13 Extended Abrupt Exit Geometry

An abrupt exit geometry as such causes inertial separation, whereby the coarse has a tendency to be reflected back into the riser while the fines tend to follow the gas streamline and exit the riser.

Brereton and Grace (1994) investigated a number of abrupt exit geometries and their corresponding solid fraction profiles. Sand particles with a $\mathrm{d}_{\mathrm{p}}$ of $148 \mu \mathrm{m}$ and $\rho_{\mathrm{s}} \approx 2650$ $\mathrm{kg} / \mathrm{m}^{3}$ were fluidized in a riser with an extended abrupt exit. Various $U_{0}$ were used to fluidize the particles; the minimum and maximum of which exceed $U_{t}$ of sand at approximately three and nine times respectively. His results indicated that the solid fraction profile had a strong dependence on the exit geometry and $\mathrm{U}_{0}$. With an extended abrupt exit and $\frac{U_{o}}{U_{t}} \approx 9$, the dimensionless solid fraction at approximately $90 \%$ dimensionless bed height was about a factor of three higher than that at $40 \%$ dimensionless bed height which had the minimum solid concentration. This 'reflux' effect extended down to approximately $60 \%$ dimensionless bed height.

The MIT cold model has an abrupt exit geometry identical to that of Brereton described above. With $\frac{U_{o}}{U_{t}} \approx 10$ (where $U_{t}$ was calculated for plastic), a similar trend has been observed.

The divergent paths of the cork and plastic is accentuated in this experiment since the cork is fine, with a terminal velocity for the largest cork, roughly $0.29 \mathrm{~m} / \mathrm{s}$, still are order of magnitude less than the superficial gas velocity. In contrast the terminal velocity of the largest plastic particles, about $3 \mathrm{~m} / \mathrm{s}$, exceeds the superficial velocity.

With a 50-50\% mixture, while samples taken at the core region did not reflect sufficient coarse (plastic) particles at all levels of the riser (i.e. the mass fraction of plastic in the sample was less than the original mixture - 50\%), samples taken in the annular region near the wall indicated a higher concentration of coarse particles. Results are shown in Figure 57. It can be seen that there is a $5 \%$ higher concentration of plastic by mass at the 
annular region as compared to the core region. The radial velocity profile peaks at the center of the riser and decreases as it gets closer to the wall. With a low velocity near the wall, coarse particles have a tendency to leave the core region for the wall. The low velocity near the wall has insufficient momentum to carry coarser and heavier particles upward. As a result, they fall and are re-circulated again within the riser. The flow behavior in this model resembles that of the core-annular flow model. In addition, sample measurements at the exhaust of the primary cyclone indicated that most of the entrained particles are finer cork (about $89 \%$ of cork and $11 \%$ of plastic by mass). These entrained particles are re-injected into the riser and are transported mostly in the core to the exit at which point they leave the riser again. This suggests that majority of the plastic particles stay within the riser near the wall.

\section{EXPERIMENTAL}

Plastics, Cork Concentrations

Samples collected were analyzed for Sauter mean particle diameter for several different cases. The majority of plastic particles tested were in the size range $>212 \mu \mathrm{m}$, while most fine cork is $<212 \mu \mathrm{m}$. In turn, a high average particle diameter indicates a stronger presence of plastic particles. In all cases run, more plastic was observed at the annular wall region than the core as indicated by the average $d_{p}$ results. Almost all of the plastic is refluxed in the riser while a substantial fraction of cork is elutriated from the riser. If the plastic and cork move at approximately the same velocity in the core and they move at the same velocity in the annulus, then there must be a higher fraction of plastic in the annulus to satisfy the mass balance at any particular cross-section.

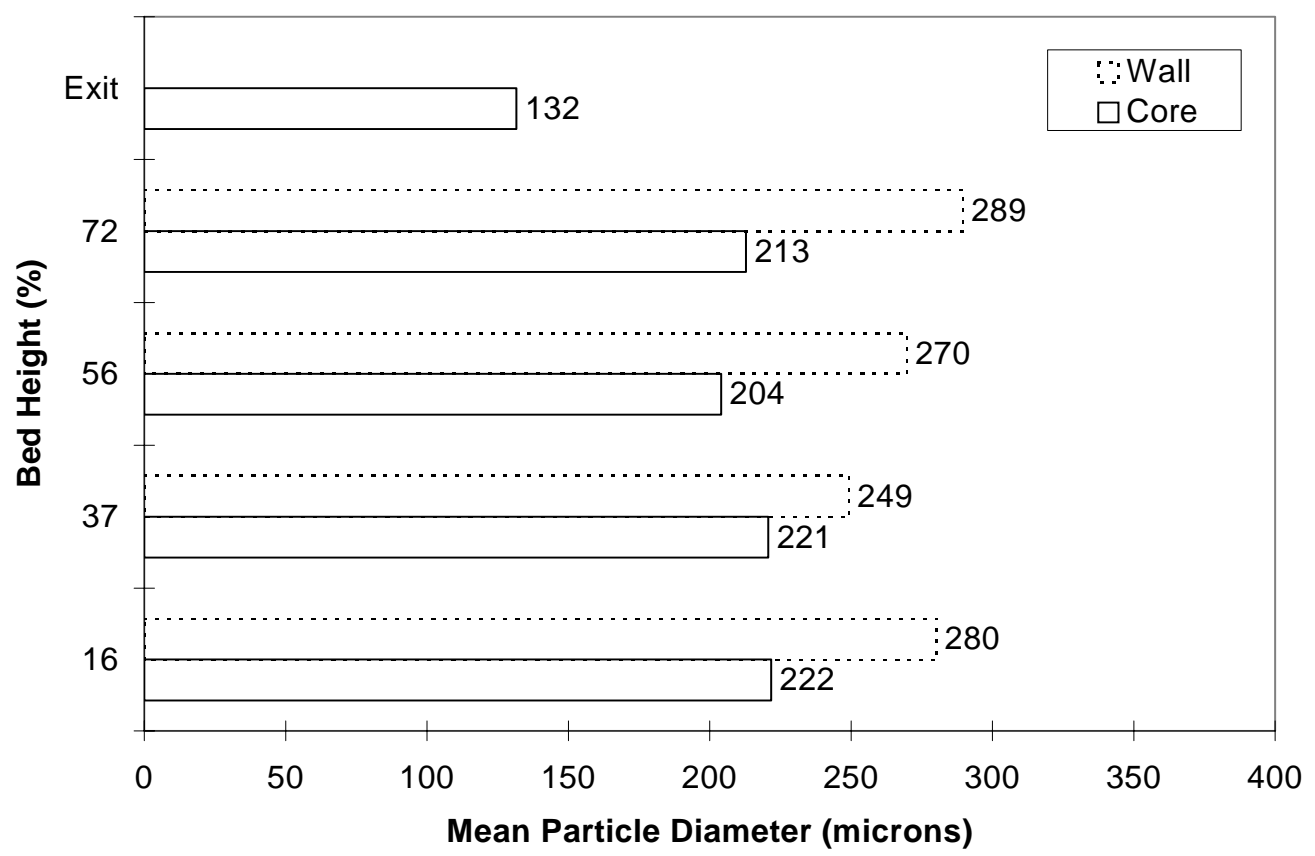

Figure 14 Average Particle Diameters for the 25\% plastic - 75\% cork mixture at low $G_{s}$ $\left(2 \pm 0.5 \mathrm{~kg} / \mathrm{m}^{2} \mathrm{~s}\right)$ and $u_{0}=2 \mathrm{~m} / \mathrm{s}$. 


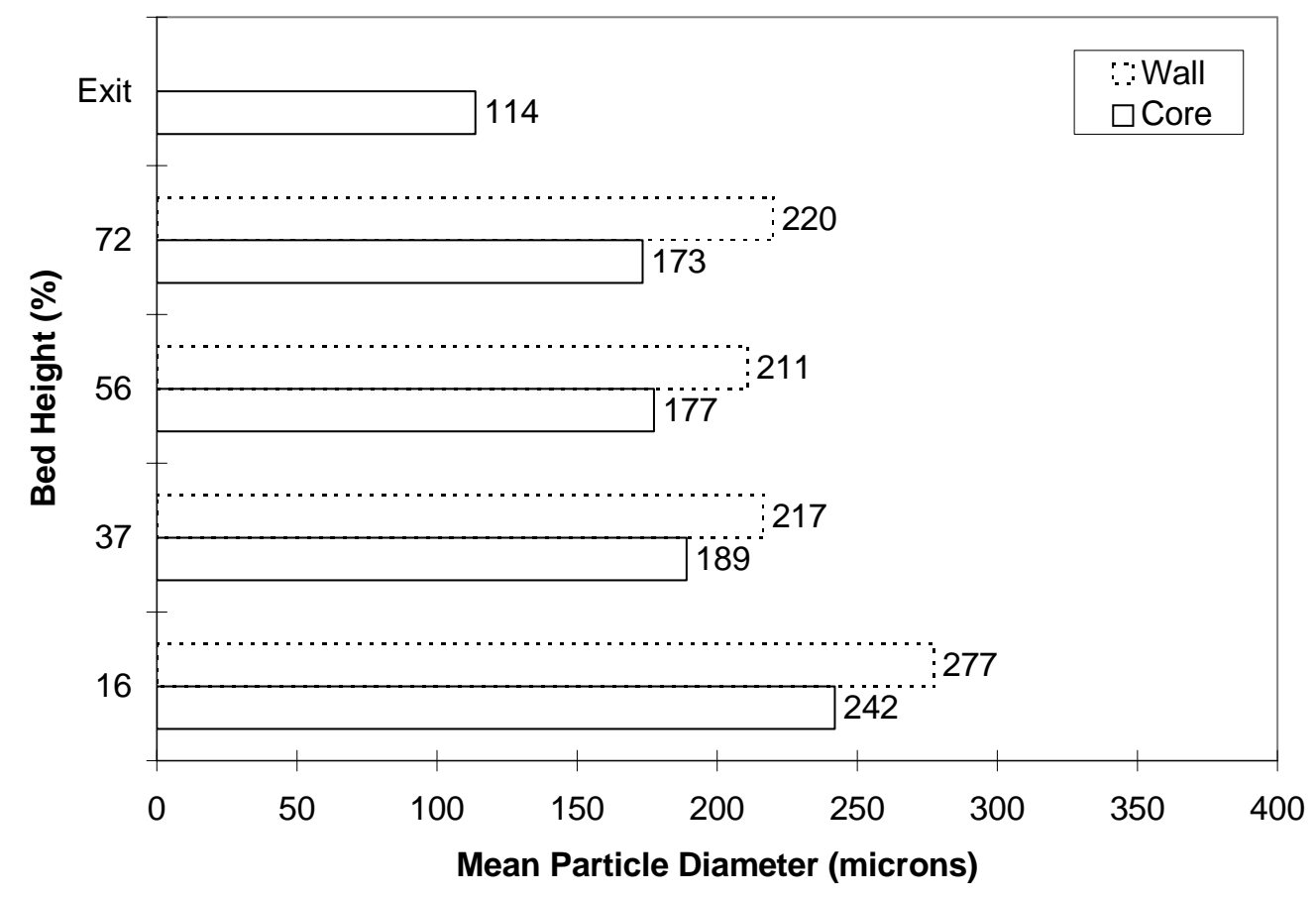

Figure 15 Average Particle Diameters for the 25\% plastic - 75\% cork mixture at high $G_{s}$ $\left(4 \pm 1 \mathrm{~kg} / \mathrm{m}^{2} \mathrm{~s}\right)$ and $u_{0}=2 \mathrm{~m} / \mathrm{s}$.

Most solid fraction data indicate higher plastic holdups towards the lower bed section (Figure 16, Figure 17, Figure 18). This can be explained in terms of their higher terminal velocities. $20 \%$ of the plastic particles are above $700 \mu \mathrm{m}$ in diameter and have terminal velocities larger than the superficial gas velocity of $2 \mathrm{~m} / \mathrm{s}$. In turn, they have a lower tendency of getting entrained high into the riser. This observation is confirmed in the average $d_{p}$ studies (Figure 14 and figure 15) and is consistent with the observations of Hirschberg et. al. (1995) who found that the tendency towards segregation is dependent on the single particle terminal velocity distribution.

The data also reveals a consistent "refluxing" trend in the coarse plastics holdup. This is most apparent in Figure 17, Figure 18 and Figure 19. At about 72\% bed height, the plastic holdup slightly increases. This phenomenon is caused by the presence of an extended abrupt exit geometry. Brereton and Grace (1994) experienced this same "reflux" effect with a similar exit geometry extending down to approximately $60 \%$ bed height. It is once again clear in the data of Hyre et. al. (1997). An abrupt exit geometry causes inertial separation, whereby the heavier coarse particles have a tendency to be reflected back into the riser while the fines tend to follow the gas streamlines and exit the riser. 


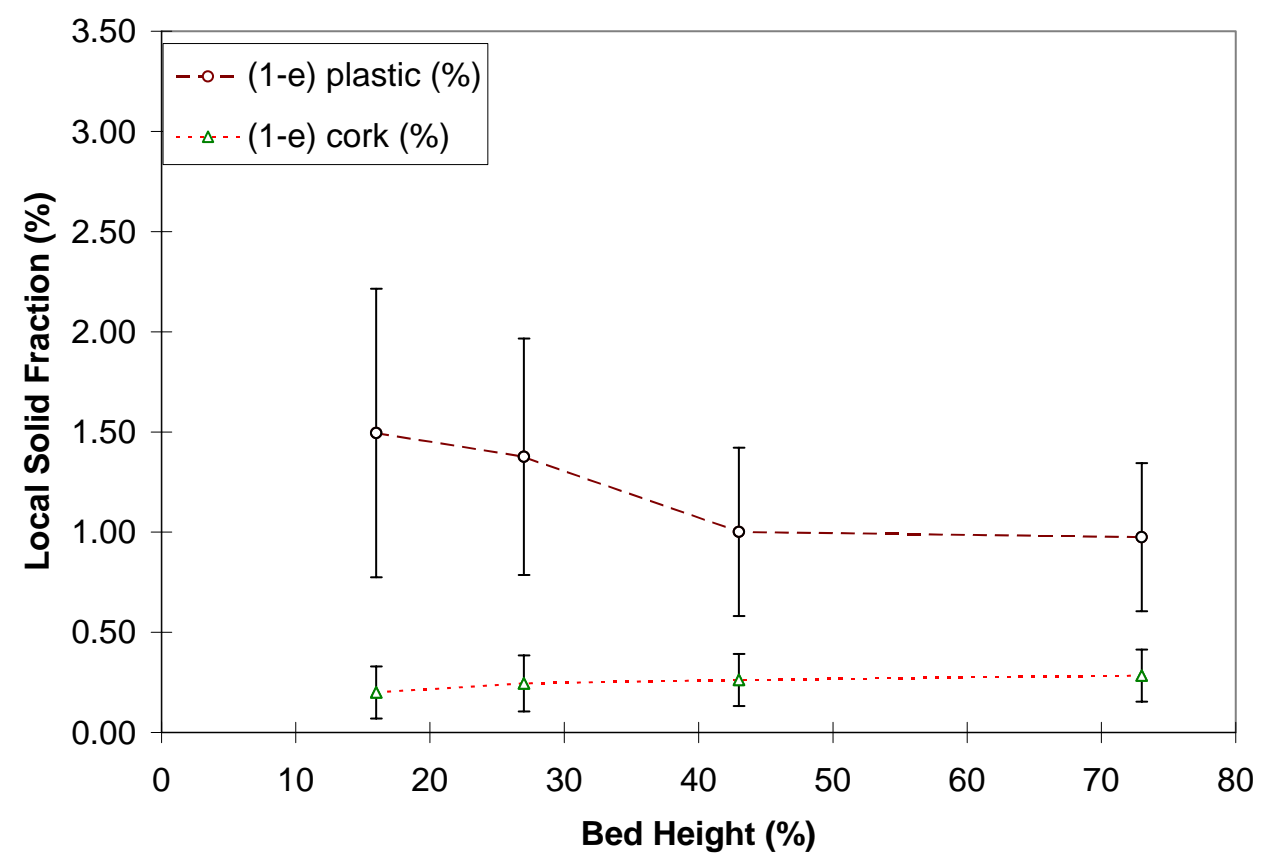

Figure 16 Individual specie solid holdup along the riser for a 50\% plastic - 50\% cork mixture at high $G_{s}\left(4 \pm 1 \mathrm{~kg} / \mathrm{m}^{2} \mathrm{~s}\right)$ and $u_{0}=2 \mathrm{~m} / \mathrm{s}$.

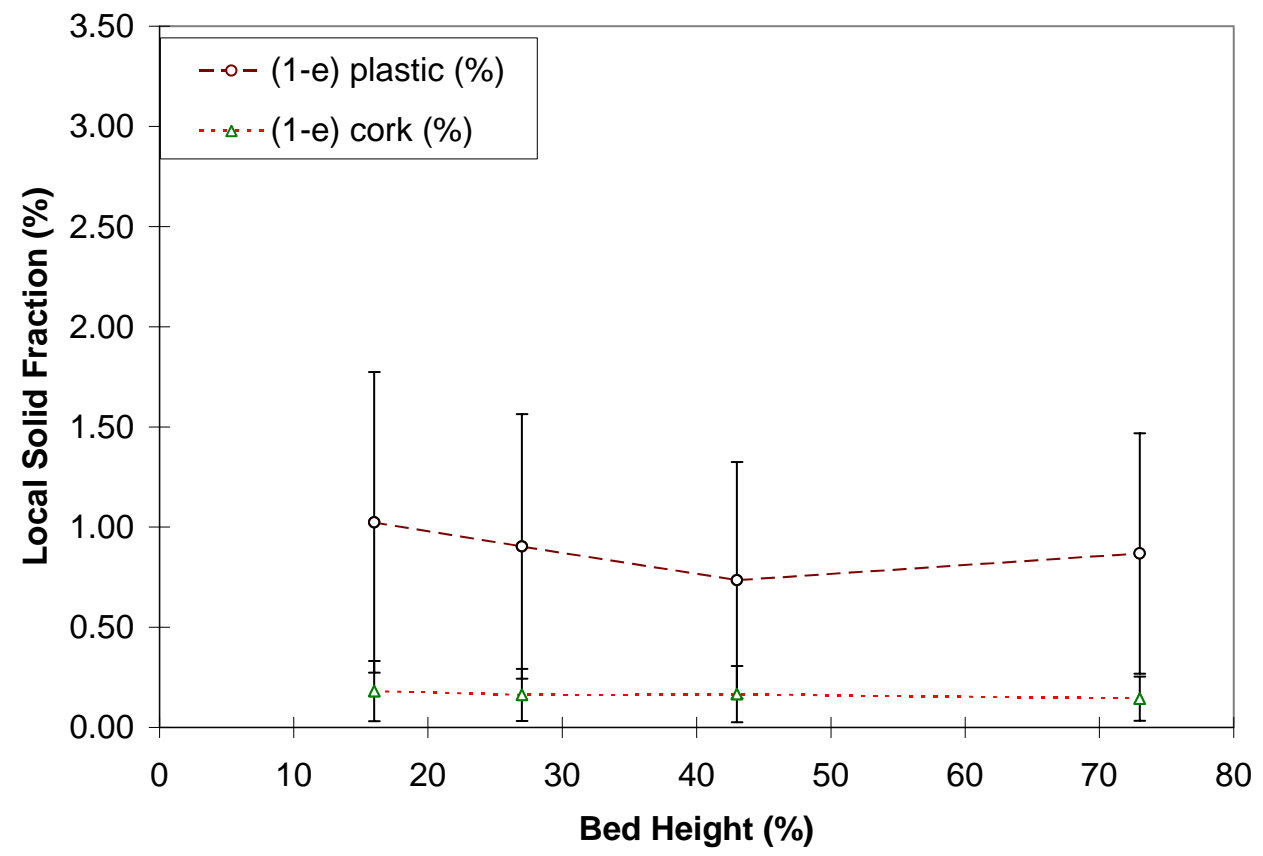

Figure 17 Individual specie solid holdup along the riser for a 50\% plastic - 50\% cork mixture at low $G_{s}\left(2 \pm 0.5 \mathrm{~kg} / \mathrm{m}^{2} \mathrm{~s}\right)$ and $u_{0}=2 \mathrm{~m} / \mathrm{s}$. 


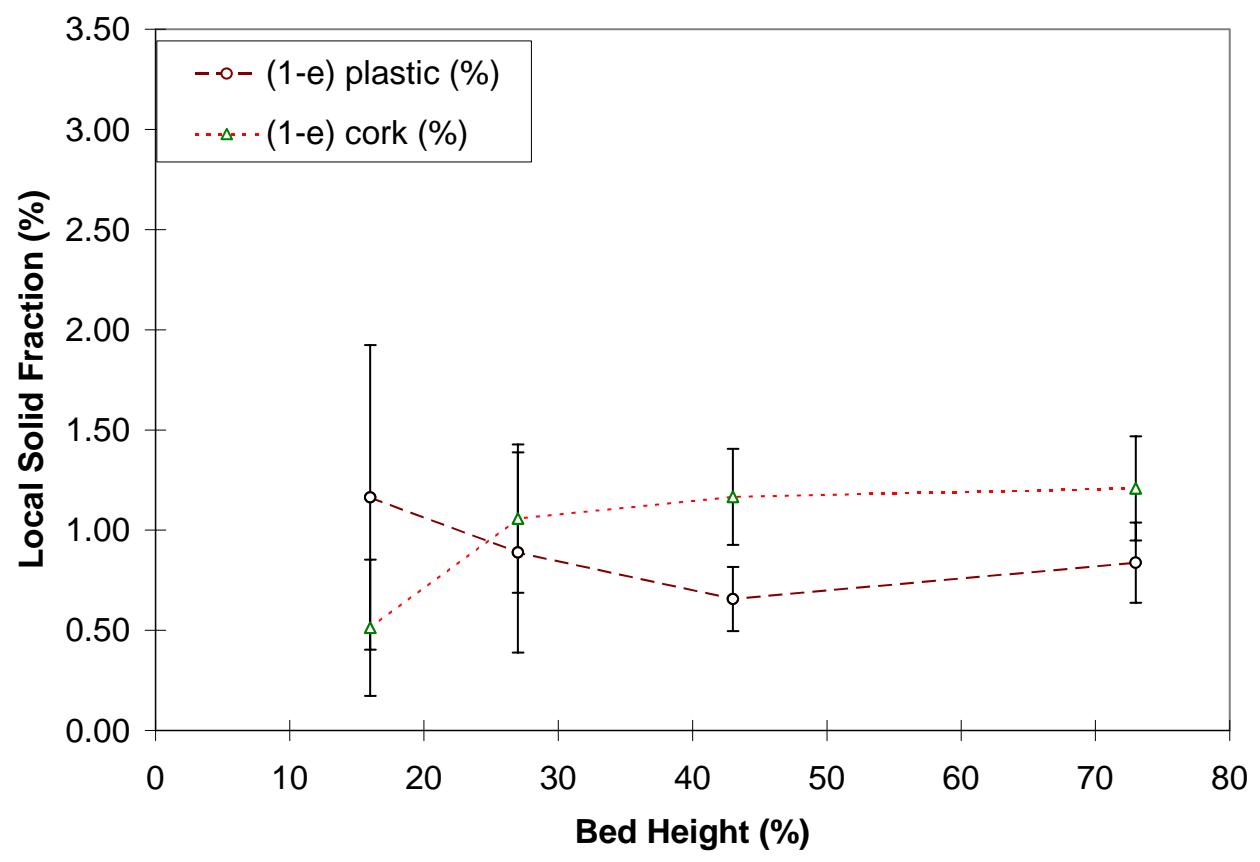

Figure 18 Individual specie solid holdup along the riser for a 25\% plastic - 75\% cork mixture at high $G_{s}\left(4 \pm 1 \mathrm{~kg} / \mathrm{m}^{2} \mathrm{~s}\right)$ and $u_{0}=2 \mathrm{~m} / \mathrm{s}$.

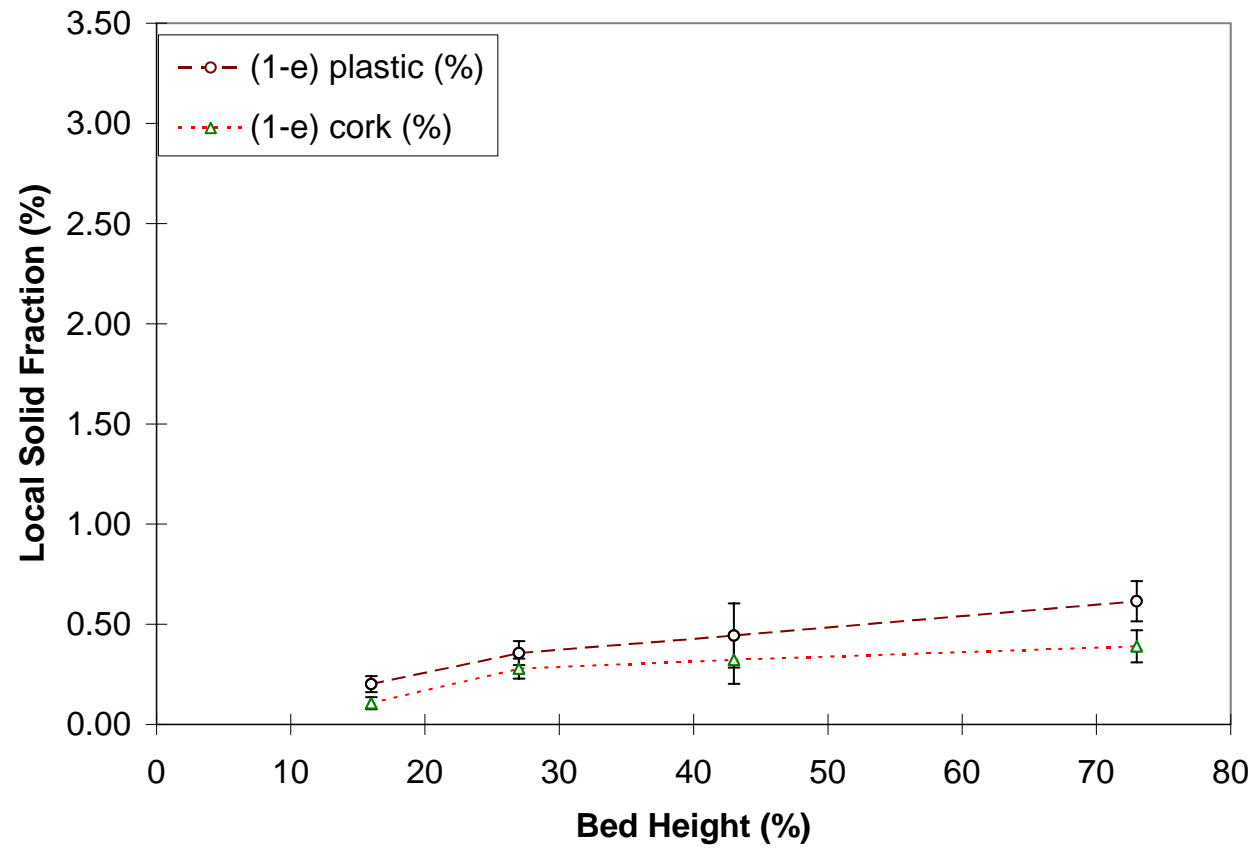

Figure 19 Individual specie solid holdup along the riser for a 25\% plastic - 75\% cork mixture at low $G_{s}\left(2 \pm 0.5 \mathrm{~kg} / \mathrm{m}^{2} \mathrm{~s}\right)$ and $u_{0}=2 \mathrm{~m} / \mathrm{s}$.

Inertial separation causes more plastic to remain in the riser while cork exits and accumulates in the return leg. An increase in $G_{s}$ would therefore inject more fines from the return leg into the riser and significantly increase their individual holdup while having a smaller increase on the holdup of plastic; that small increase probably resulting from plastic-cork particle interactions. This conclusion holds well and can be seen when 
comparing Figure 18 and Figure 19 with $G_{s}$ as the only parameter varied. Increasing the solids recycle rate has a small effect on the plastic holdup but approximately doubles the holdup of fine cork (true except when comparing the first data point of Figure 19). This is supported by the average $d_{p}$ data; the mean $d_{p}$ of each sample everywhere along the riser drops with increasing $G_{s}$.

Finally, the effect of mixture composition is noted. Comparison of Figure 16 and Figure 18 as well as Figure 17 and Figure 19 where the only parameter varied was mixture composition reveals an upward shift in the plastic holdup when increasing the initial loading of plastic particles from 25\% to 50\%. An opposite downward shift of fine cork holdup is also observed. In addition, increasing the initial loading causes more plastic to exit the riser.

\section{Model Description}

In parallel to the experimental work, a numerical model has been developed to predict the vertical solid distribution in the core and the annulus. In this model, the dilute region of the bed is divided into $\mathrm{N}$ elements. Each element is further divided into a core and annular region (Figure 20) of solids fractions, $\varepsilon_{c s}$ and $\varepsilon_{a s}$, respectively.

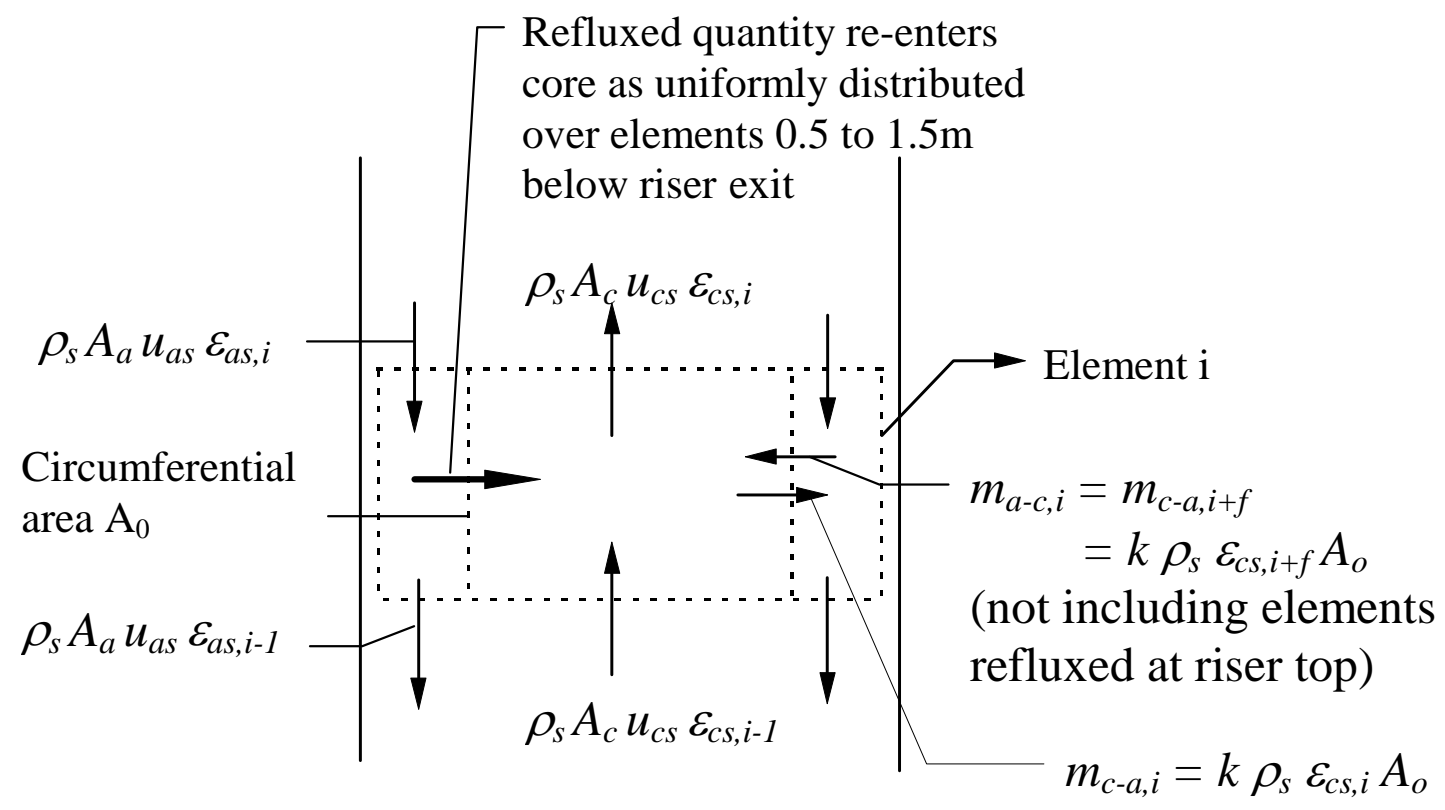

Figure 20 A typical element showing the core-annulus division.

A number of initial assumptions are made in order to simplify the model. The core is assumed to occupy a fraction $\alpha_{c}=A_{c} / A_{r}$ equal to 0.9 of the riser cross-sectional area. The percentage of solids exiting the riser, $x$ (see Figure 21) is assumed to have a value of $10 \%$ for the coarse plastic and 95\% for the finer cork particles. This is based on the measurement (using our ninth sampling port at the riser exit) that most of the finer cork particles follow the gas streamlines and exit the riser, while the coarse plastic undergoes inertial separation and refluxes back into the riser (Younis et. al, 1998). The velocity of the annular downflowing film is fixed at $1.5 \mathrm{~m} / \mathrm{s}$, which is within the range of $1-2 \mathrm{~m} / \mathrm{s}$ measured by several investigators, independent of their operating conditions (e.g. Noymer and Glicksman, 1996; Yang et. al., 1992; Hartge et. al., 1988). The velocity of solids in the core, $u_{c s}$, is the slip velocity of the particles, calculated based on mean particle diameter, $\mathrm{d}_{\mathrm{p}}$. 


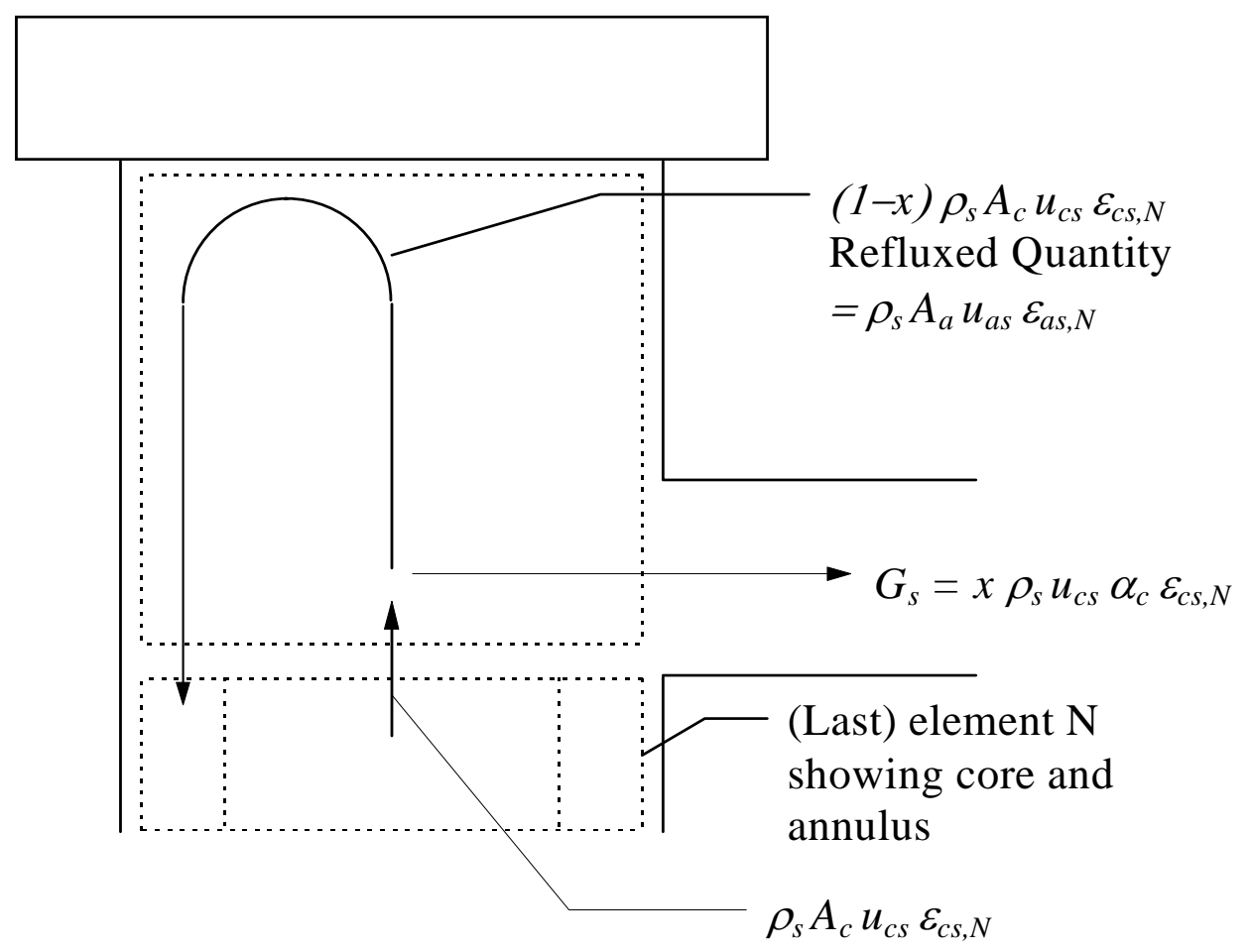

Figure 21 Mass balance at riser exit.

Noymer and Glicksman (1996) have found that, on average, a cluster that forms at the wall stays there for approximately $1 \mathrm{~m}$ before it departs and re-enters the core. This result was used to equate the mass inflow into the core from the annulus at a particular element, $m_{a-c, i}$ to the quantity deposited from the core into the annulus, $m_{c-a, i+f}, 1 \mathrm{~m}$ higher up in the bed; $\mathrm{f}$ being the number of elements in $1 \mathrm{~m}$. Similarly, the refluxed quantity at the riser top end ( Figure 21) was treated as a uniform distribution that re-enters the core over elements 0.5 to $1.5 \mathrm{~m}$ below the riser exit.

In estimating the core-annulus deposition rate, an expression similar to that proposed by Harris and Davidson (1993) is used, where $m_{c-a}$ is proportional to the core solids fraction, $\varepsilon_{c s}$ :

$$
m_{c-a}=k \rho_{s} \varepsilon_{c s} A_{0}
$$

$k$ is a deposition coefficient estimated from typical values obtained by a model proposed by Hyre and Glicksman (1997). The model tracks particles through the turbulent flow field using a particle/eddy interaction time to describe the effect of the interaction between the particles and the fluid, and uses a collisional timescale to describe the effect of particle collisions. Running this mechanistic model yielded values of $k=0.025 \mathrm{~m} / \mathrm{s}$ for plastic and $0.067 \mathrm{~m} / \mathrm{s}$ for cork at the specific conditions described in Figure 22 and Figure 23.

Having specified all the necessary parameters to proceed, mass balances on the core and annulus for each specie yield the following equations: 
Core mass balance

$$
\rho_{s} A_{c} u_{c s}\left(\varepsilon_{c s, i}-\varepsilon_{c s, i-1}\right)=\frac{(1-x) \rho_{s} u_{c s} A_{c} \varepsilon_{c s, N}}{f}+m_{a-c, i}-m_{c-a, i}
$$

The reflux term $\frac{(1-x) \rho_{s} u_{c s} A_{c} \varepsilon_{c s, N}}{f}$ enters only in elements that are 0.5 to $1.5 \mathrm{~m}$ lower than the riser exit. In addition the $m_{a-c, i}$ term only appears in elements $1 \mathrm{~m}$ below the riser exit and is equated to $m_{c-a, i+f}$ as described above.

The equations are then arranged in matrix form to solve for the $\varepsilon_{c s}$ vector for all vertical elements. To start the calculation, it is necessary to assume the bottommost core solids fraction, $\varepsilon_{c s, 0}$. For every $\varepsilon_{c s, 0}$, a unique $\varepsilon_{c s}$ vector is obtained. The solids recycle rate $G_{s}$ is then computed from $\varepsilon_{c s, N}$ as shown in Figure 21. The value of $\varepsilon_{c s, 0}$ is consecutively changed until the required (experimental) $G_{s}$ is matched. This analysis is valid only above the dense lower region of the bed. $\varepsilon_{c s, 0}$ represents the core solid fraction at the top of the dense region, $0.7 \mathrm{~m}$ from the distributor.

\section{Annular mass balance:}

Once the value of $\varepsilon_{c s, N}$ is obtained as described above, the refluxed quantity is assumed to solely enter the annular layer and $\varepsilon_{a s, N}$ can be solved for by (see also Figure 21):

$$
(1-x) \rho_{s} A_{c} u_{c s} \varepsilon_{c s, N}=\rho_{s} A_{a} u_{a s} \varepsilon_{a s, N}
$$

A mass balance on each annular element then allows for the remaining values of $\varepsilon_{a s}$ to be found, working from the top of the riser down:

$$
\rho_{s} A_{a} u_{a s} \varepsilon_{a s, i-1}=\rho_{s} A_{a} u_{a s} \varepsilon_{a s, i}-\frac{(1-x) \rho_{s} u_{c s} A_{c} \varepsilon_{c s, N}}{f}-m_{a-c, i}+m_{c-a, i}
$$

Once again, the reflux term appears only in elements that are 0.5 to $1.5 \mathrm{~m}$ lower than the riser exit and the $m_{a-c, i}$ term only appears in elements $1 \mathrm{~m}$ below the riser exit.

The overall local solids holdup, å, is then computed by:

$$
\varepsilon=\frac{A_{c} \varepsilon_{c s}+A_{a} \varepsilon_{a s}}{A_{r}}
$$

A limitation of this algorithm is that the solid fractions for each specie are solved for independently, decoupling the interaction between the cork and plastic particles. It is expected that collisions between the different size particles moving at different velocities in the core will influence the deposition constant, $k$. Nevertheless, reasonable agreement is obtained with the experimental data as is shown in the next section. 


\section{Data and Results}

The experimental solid fraction data indicates higher plastic holdups towards the lower bed section (see Figure 22 ). This can be explained in terms of their higher terminal velocities. $20 \%$ of the plastic particles are above $700 \mu \mathrm{m}$ in diameter and have terminal velocities larger than the superficial gas velocity of $2 \mathrm{~m} / \mathrm{s}$. They have a lower tendency of getting entrained high into the riser. This observation is consistent with the observations of Hirschberg et. al. (1995) who found that particles with terminal velocities greater than the superficial gas velocity tend to accumulate in the lower bed region. The model fails to capture this dependence since an average particle diameter for plastic of $283 \mu \mathrm{m}$ is used; with a corresponding $u_{t}$ of $0.9 \mathrm{~m} / \mathrm{s}$.

However, in the case of the finer cork, the superficial gas velocity exceeds the terminal velocity for all particle diameters used. The result is a more uniform solids holdup as can been seen in the experimental data and as predicted by the model (Figure ).

The agreement of the model predictions with the experimental data is better in the case of plastic (Figure 22) than cork (see discrepancy on Figure 23). The model was run separately for each specie (i.e. binary specie collisions were not considered). The cork has a small effect on plastic holdups. This is mainly due to the low inertia of the cork. It does not have the ability to drastically change the motion of the much higher inertia plastic.

The data also reveals a "refluxing" trend in the coarse plastics holdup. At about $72 \%$ bed height, the plastic holdup slightly increases. This phenomenon is caused by the presence of an extended abrupt exit geometry. Brereton and Grace (1994) experienced this same "reflux" effect with a similar exit geometry extending down to approximately $60 \%$ bed height. It is once again clear in the data of Hyre et. al. (1997). An abrupt exit geometry causes inertial separation, whereby the heavier coarse particles have a tendency to be reflected back into the riser while the fines tend to follow the gas streamlines and exit the riser. The values of $x$ used with the model illustrate this behavior, showing a much smaller reflux effect in the case of cork (Figure 23). All error bars presented are $\pm 2 \sigma$.

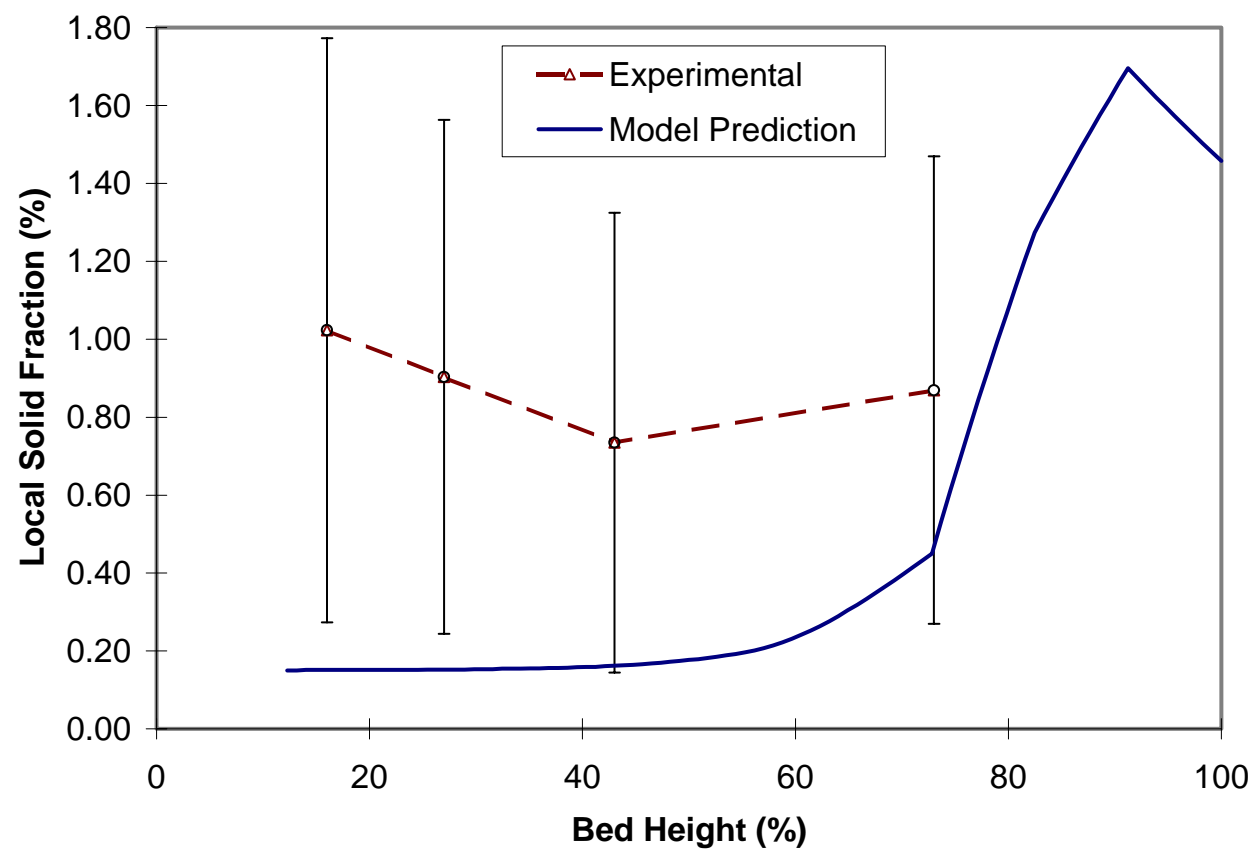


Figure 22 Plastic solid holdup along the riser for a 50\% plastic - 50\% cork mixture at $G_{s, p}=0.9 \mathrm{~kg} / \mathrm{m}^{2} \mathrm{~s}\left(G_{s, t o t a l}=2.1 \mathrm{~kg} / \mathrm{m}^{2} \mathrm{~s}\right), k=0.025 \mathrm{~m} / \mathrm{s}$ and $u_{0}=2 \mathrm{~m} / \mathrm{s}$.

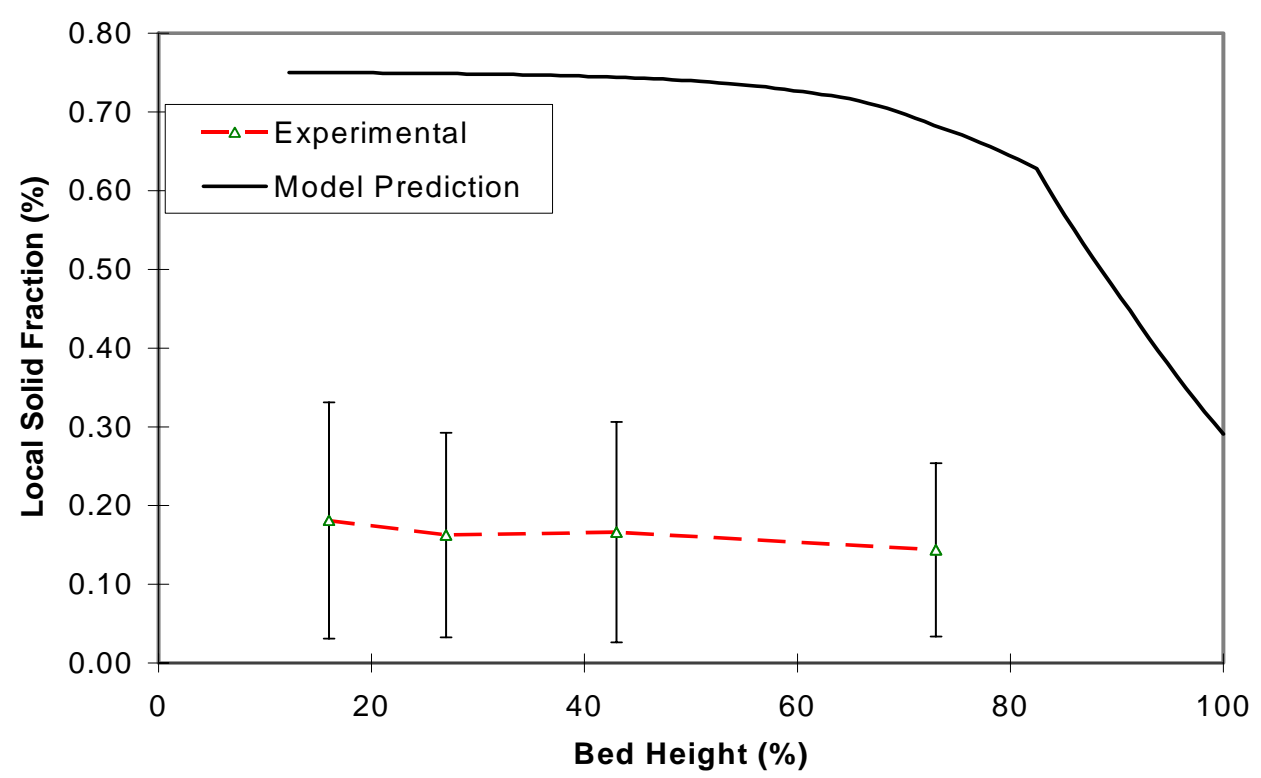

Figure 23 Cork solid holdup along the riser for a 50\% plastic - 50\% cork mixture at $G_{s, c}=1.2 \mathrm{~kg} / \mathrm{m}^{2} \mathrm{~s}\left(G_{s, t o t a l}=2.1 \mathrm{~kg} / \mathrm{m}^{2} \mathrm{~s}\right), k=0.067 \mathrm{~m} / \mathrm{s}$ and $u_{0}=2 \mathrm{~m} / \mathrm{s}$.

\section{Conclusion}

Foster Wheeler Corporation's High Performance Power System (HIPPS) pressurized fluidized bed pyrolyzer was successfully modeled in a lab scale cold model. Tests were conducted to investigate the effect of the major operating parameters on the hydrodynamic behavior of binary solids for the circulating mode of operation. A higher presence of plastic is detected both at the wall and lower bed regions of the riser due to two distinct phenomena. The effect of an abrupt riser geometry is also noted and causes the "refluxing" of coarse plastic within the riser while allowing the finer cork to escape to the return leg. Consequently, raising the solids recycle rate increases the holdup of fine cork with a small impact on plastic holdup.

\section{Acknowledgments}

This work was funded by the U.S. Department of Energy, National Energy Technology Laboratory, under grant number DE-FG22-95PC95228

\section{Nomenclature}

$A_{c} \quad$ cross-sectional area of core region.

$A_{0} \quad$ circumferential area of core-annulus interface for a single element

$A_{a} \quad$ cross-sectional area of annular region

$A_{r} \quad$ cross-sectional area of riser

$\rho_{s} \quad$ solid density

$\rho_{p} \quad$ plastic material density

$\rho_{c} \quad$ cork material density

$\rho_{f} \quad$ gas density

$\mu \quad$ fluid viscosity

$u_{0} \quad$ superficial gas velocity

$u_{m f} \quad$ minimum fluidization velocity 


$\begin{array}{ll}u_{t} & \text { single particle terminal velocity } \\ u_{c s} & \text { slip velocity of particles in the core } \\ u_{a s} & \text { velocity of downflowing annular film } \\ g & \text { acceleration due to gravity } \\ G_{s} & \text { solids recycle rate } \\ G_{s, c} & \text { cork solids recycle rate } \\ G_{s, p} & \text { plastic solids recycle rate } \\ D & \text { bed diameter } \\ L & \text { bed height } \\ \phi_{s} & \text { particle sphericity } \\ \phi & \text { sampling probe diameter } \\ d_{p} & \text { particle diameter } \\ \text { PSD } & \text { particle size distribution } \\ \Delta P & \text { differential pressure drop } \\ \Delta h & \text { distance between pressure transducers } \\ e & \text { cross-sectionally averaged void fraction } \\ (1-e)_{p} & \text { local plastic solid fraction (coarse) } \\ (1-e)_{c} & \text { local cork solid fraction (fines) } \\ x_{p} & \text { average mass fraction of plastic } \\ N & \text { number of elements in dilute region (100) } \\ f & \text { number of elements in 1m. } \\ \alpha & \left.\text { core fraction (=A } A_{r}\right) \\ s c s, i & \text { solid fraction - core region for element i } \\ \varepsilon a s, i & \text { solid fraction in annular region for element i } \\ k & \text { deposition coefficient } \\ x & \text { percentage of solids exiting riser } \\ m_{c-a} & \text { mass flow rate from core to annulus } \\ m_{a-c} & \text { mass flow rate from annulus to core }\end{array}$

\section{References}

Bai, D., Nakagawa, N., Shibuya, E., Kinoshita, H. and K. Kato, "Axial Distribution of Solid Holdups in Binary Solids in Circulating Fluidized Beds," J. of Chem. Engng. Jap., 27, 271-271 (1994).

Brereton, C. and J.R. Grace, "End Effects in Circulating Fluidized Bed Hydrodynamics," Proceedings of the $4^{\text {th }}$ Intl. Conf. on Circulating Fluidized Beds, Somerset, Pennsylvania, 137-144 (1994).

Glicksman, L.R., "Scaling relationships for Fluidized Beds," Chemical Engng Sci., 39, 1373-1379 (1984).

Glicksman, L.R., "Scaling relationships for Fluidized Beds," Chemical Engng Sci., 43, 1419-1421 (1988).

Glicksman, L.R., Hyre, M.R., and K. Woloshun, "Simplified Scaling relationships for Fluidized Beds," Powder Technol., 77, 177-199 (1993).

Harris, B.J. and J.F. Davidson, "A Core/Annulus Deposition Model for Circulating Fluidized Beds," Proceedings of the $4^{\text {th }}$ Intl. Conf. on Circulating Fluidized Beds, Somerset, Pennsylvania, 32-39 (1993). 
Hartge, E.-U, Rensner, D., and Werther, J., “Solids Concentration and Velocity in Circulating Fluidized Beds,” Proceedings of the $2^{\text {nd }}$ Intl. Conf. On Circulating Fluidized Beds, 165-180, Compiegne, France (1988).

Hirschberg, B., Werther, J., Delebarre, A., and A. Koniuta, "Mixing and Segregation of Solids in a Circulating Fluidized Bed," Fluidization VIII: Proceedings of the Eighth Engineering Foundation Conference on Fluidization, Tours, France, 281-290 (1995).

Horio, M., Nonaka, A., Sawa, Y. and I. Muchi, "A New Similarity Rule for Fluidized Bed Scale-up," AIChE Jl., 32, 1466-1482 (1986).

Horio, M., Ishii, H., Kobukai, Y., and N. Yamanishi, "A Scaling Law for Circulating Fluidized Beds," Chem Engng. Jap., 22, 587-592 (1989).

Hyre, M.R., and L.R. Glicksman, "Determination of Lateral Dispersion Coefficients in the Dilute region of Fluidized Beds," Proceedings of the 1997 AIChE Winter Annual Meeting, Los Angeles, CA (1997).

Hyre, M.R., Glicksman, L.R., and M. Torpey, "Use of Simplified Scaling laws to Examine the Hydrodynamics of Pressurized Circulating Fluidized Beds," Proceedings of the 1997 ASME Intl. conf. on Fluidized bed Combustion, Vancouver, Canada (1997).

Noymer, P.D. and L.R. Glicksman, "Measurements of Cluster-Wall Contact Time in a ScaleModel Circulating Fluidized Bed," ASME Annual Meeting, Atlanta, GA (1996).

Scharff, M.F., Goldman, S.R., Flanagan, T.M., Gregory, T.K., and L.D. Smoot, "Project to Provide an Experimental Plant for the MERC 6' x 6' Fluidized Bed Cold Test Model," Final Report J77-2042-FR, U.S. Department of Energy, Contract EY-77-C-21-8156 (1978).

Yang, Y.L., Jin.Y., Yu, Z.-Q., and Wang, Z.W., "Investigation of the Slip Velocity in the Riser of a Dilute CFB,” Powder Technol., 73, 67-73 (1992).

Younis, H.F., Tan, R.H., and L.R. Glicksman, "Experimental Simulation of the Hydrodynamics of Dissimilar Solids in a Pressurized Circulating Fluidized Bed," presented at the PTF Topical Conference at the 1998 AIChE Annual Meeting, Session on Fluidized Bed Combustion, Miami, FL (1998). 